Defraeye T., Verboven P., Derome D., Carmeliet J., Nicolai B., Stomatal transpiration and droplet evaporation on leaf surfaces by a microscale modelling approach, International Journal of Heat and Mass Transfer 65, 180-191. http://dx.doi.org/10.1016/j.ijheatmasstransfer.2013.05.075

\title{
Stomatal transpiration and droplet evaporation on leaf surfaces by a microscale modelling approach
}

\begin{abstract}
$\underline{\text { Abstract }}$
Knowledge on convective water vapour exchange at leaf-air interfaces is required to assess transpiration of leaves via stomata and evaporation of droplets, which can both be considered as microscopic moisture sources, heterogeneously distributed across the leaf. An innovative modelling approach was proposed to investigate such convective mass transport from leaf surfaces, using computational fluid dynamics (shear-stress transport k- $\omega$ turbulence model with lowReynolds number modelling). The main novelty lies in the fact that a large range of spatial scales $\left(10^{-5} \mathrm{~m} \mathrm{to} 10^{-1} \mathrm{~m}\right)$ was included. The convective exchange from the leaf model was strongly dependent on three parameters: surface coverage, air speed and source size. The relation between the convective flow rate and both the coverage ratio (CR) and the microscopic Sherwood number, i.e., the ratio of the source size to the viscous sublayer thickness, was quantified. It was shown that well-established convective transfer coefficients, obtained from plates or leaf models for a CR of 100\%, can result in a significant overprediction of the convective exchange, compared to more realistic, lower CR. Furthermore, small variations in stomatal density (CR), e.g., due to biological variability, were shown to have a large impact on the convective exchange and droplets were found to evaporate more rapidly at low $\mathrm{CR}$. The decrease in mass transfer rate due to stomatal closure was quantified as well. The proposed numerical modelling approach can be applied to increase our understanding of leaf transpiration and droplet evaporation, but also of the leaf boundary-layer microclimate and the transport processes therein. A critical discussion of the modelling assumptions allowed to identify focus points for future model refinement as well as future research.
\end{abstract}

\section{Keywords}

Convective transfer coefficient; Plant; Computational fluid dynamics; Mass; Convective exchange; Boundary layer

\section{Highlights}

- A computational approach was developed to study exchange at stomata and droplets

- Conventional convective transfer coefficients often overpredict exchange rates of leaves

- A microscale modelling framework provided new insight in exchange processes at leaf surfaces

- The convective exchange rate was dependent on source size, coverage and air speed

- Correlation between exchange rate and microscopic Sherwood number was identified 
Defraeye T., Verboven P., Derome D., Carmeliet J., Nicolai B., Stomatal transpiration and droplet evaporation on leaf surfaces by a microscale modelling approach, International Journal of Heat and Mass Transfer 65, 180-191. http://dx.doi.org/10.1016/j.ijheatmasstransfer.2013.05.075

\section{Introduction}

Accurate predictions of evapotranspiration processes from leaves, via stomata and droplets, are of interest for plant physiology, hydrology, agricultural production, boundary-layer meteorology and biosystems engineering. Stomata and small droplets on leaves are both distributed heterogeneously across the leaf surface and are of a small (microscopic) scale. They can be considered as discrete moisture sources at the leaf surface: leaf transpiration occurs predominantly via stomata, and evaporation occurs at droplet surfaces. The aim of this study is to increase our understanding of the convective water vapour exchange via these microscopic sources at the leaf-air interface, and its impact on the average moisture transfer from the leaf surface to the environment. For this purpose, we investigate the hypothesis that the exchange rate has a complex dependency on the size of the stomata/droplets, their surface coverage and the air speed. Such dependencies have not yet been identified in detail.

Stomata are local elliptical perforations in the epidermis and have sizes of a few tens of micron. They occupy one to a few percent of the leaf surface area, with a density of $10^{1}-10^{2}$ stomata per $\mathrm{mm}^{2}$ (e.g., [1]). The density can differ for upper (adaxial) and lower (abaxial) leaf surfaces. The bulk of the leaf moisture loss occurs via transpiration through the stomata, as the cuticle is quasi impermeable. Stomata thus play an important role in the plant hydrological cycle [2] and influence plant water uptake and water stress, which is the single most important problem in agricultural production [3]. The transpiration rate is mainly determined by the stomatal resistance, which is predominantly dependent on the stomatal aperture. The complex regulatory mechanism of opening and closing of the stomata is not fully understood yet [1-2]. The transpiration rate is however also dependent on the air flow conditions above the leaf surface, and thus the convective mass exchange between stomata and the environment - the resistance offered by the boundary layer [4-7]. This convective vapour exchange has been found to be mainly dependent on the stomatal aperture and density, and on the boundary-layer microclimatic conditions around the stomata, and is a subject of active research [8-9].

Droplets are deposited on leaves by rain, dew, or artificially, e.g., from pesticide spraying, and have sizes ranging from very small $\left(10^{-4} \mathrm{~m}\right)$ to a few millimetres [10-14]. Knowledge on droplet evaporation from leaf surfaces is required to assess evapotranspiration processes and plant/tree leaf water budgets. Water availability at leaf surfaces also determines the boundary-layer microclimate, and the risk of contamination by pathogens or other infections. Furthermore, the evaporation kinetics of pesticide droplets, thus the droplet lifetime, determines pesticide efficacy [1517]: fast evaporation can result in insufficient droplet spreading, reduced absorption of active chemical components or formation of crystals, whereas slow evaporation may induce germination of pathogens. An understanding of the convective exchange at the air-droplet interface is critical here, as it governs the droplet evaporation kinetics.

As stomata and droplets are distributed discretely over the leaf surface, they both lead to a very heterogeneous (nonuniform) mass exchange over the leaf surface, predominantly at the microscale level $\left(10^{-5}-10^{-3} \mathrm{~m}\right)$. The impact of these point sources on the convective exchange is usually not considered by conventional convective transfer studies on leaves [9]: for real leaves, measurements of individual droplet evaporation/stomatal transpiration rate and stomatal aperture are not straightforward, which explains why usually only leaf-averaged transfer is assessed; for numerical studies or experimental studies using artificial leaves, homogeneous mass boundary conditions are usually imposed at the leaf surface, such as a uniform distribution of water vapour pressure over the entire surface. Although the mass transfer from a leaf can be up to 2.5 times higher than from a flat plate [9], the impact of the discrete distribution of the 
stomata (or droplets) on the transfer rate has not yet been isolated, as other influence factors, such as surface roughness, edge effects, leaf curvature, leaf orientation or flutter, inherently contribute as well [18-19].

Only a few researchers investigated in detail the effect of such discretely-distributed moisture sources on mass transfer, mainly for applications related to droplet evaporation. An analytical study by Schlünder [20] showed that for laminar boundary-layer flow over a flat surface, a high mass transfer rate could be obtained for a partially-wetted surface under specific conditions, by which the surface behaved very similar to a uniformly-wetted surface. Cannon et al. [21] developed an analytical model to describe transpiration from leaf stomata into the boundary layer, including transport in the substomatal cavities. This model was used to investigate boundary-layer interference effects between stomata. Such analytical considerations are, however, limited to simple air flow configurations, (usually laminar and two-dimensional). A few experimental studies were also performed, as detailed in Table 1. These studies looked only at air-side transfer, except Cannon et al. [21], which in addition mimicked the transport from the substomatal cavity through the stomata by using microscopically perforated plates.

The aforementioned experimental studies mainly considered macroscale moisture sources $\left(>10^{-3} \mathrm{~m}\right)$. Furthermore, only the total convective transfer rate was determined. An experimental assessment of the boundary-layer flow and the local exchange processes therein, which determine the microclimate around the droplets and stomata, was not performed as this is very challenging at such small scales. Numerical modelling would partially alleviate these limitations, which could provide new insights. This is the perspective of the present study. With computational fluid dynamics (CFD), (passive) convective mass exchange in the boundary layer will be modelled from leaf level $\left(10^{-1} \mathrm{~m}\right)$ down to the stomatal scale $\left(10^{-5} \mathrm{~m}\right)$, thus covering a very large spatial range for a numerical study. Apart from quantifying the mass flow from the sources at the interface, high spatial resolution information is obtained on the flow field and the mass transport therein. By such numerical modelling, a systematic study is undertaken to identify the effect of the size of the stomata or small droplets, their surface coverage and the air speed on their convective exchange. To the knowledge of the authors, the only numerical study undertaken to quantify transpiration via microscopic sources [8] only considered the microscale level, as it modelled stomata arranged in a single stomatal crypt and investigated their effect on the crypt conductance. The main novelty of the computational modelling approach presented in this study lies in the fact that a very large spatial range is covered.

\section{Materials and methods}

\subsection{Numerical model}

\section{$\underline{\text { 2.1.1 Computational domain }}$}

A simplified configuration was used to investigate convective water vapour (i.e., scalar) transfer from microscopic sources at a leaf surface: a 2D flat plate representing a leaf (length $L=0.1 \mathrm{~m}$ ) was placed flush in two-dimensional channel flow (channel height $H=0.5 \mathrm{~m}=5 L$ ). The $2 \mathrm{D}$ computational domain is presented in Figure $1 \mathrm{~b}$, together with the imposed boundary conditions. The domain dimensions and the computational grid were based on best practice guidelines [22] and grid sensitivity analysis. An upstream $(L / 2)$ and downstream channel section $(5 L)$ were provided to avoid an influence of the imposed boundary conditions at inlet and outlet on the momentum and scalar transfer in the vicinity of the leaf. The grid is composed out of quadrilateral cells and contains $2.26 \times 10^{5}$ cells. From grid sensitivity 
analysis, the spatial discretisation error was estimated by means of Richardson extrapolation [23-24], and is below $0.6 \%$ for both leaf drag force and scalar flux at the wall.

\section{$\underline{\text { 2.1.2 Computational grid }}$}

\section{Microscopic sources on leaf surface}

To model discretely-distributed microscopic scalar sources on the leaf surface, representative for stomata or small droplets, very small computational cells of uniform dimensions were used on this surface. Stomata typically have a diameter of a few tens of micron when fully open; droplets have sizes (diameter) of about $10^{-4} \mathrm{~m}$ to a few millimetres (see section 1). Thereto, a cell size $(d)$ of $10 \times 10^{-6} \mathrm{~m}$ was used on the leaf surface in the computational model and by grouping several of these cells, larger sources could be created (see section 2.1.4). Including such a large range of spatial scales in the same computational model $\left(10^{-5} \mathrm{~m}\right.$ to $\left.10^{-1} \mathrm{~m}\right)$ is particularly challenging with respect to grid generation. The grid in the boundary-layer region is shown in Figure 2, and more details are presented in Appendix 1. Several transition regions were applied away from the leaf surface to reduce the number of cells in the computational model and to avoid very elongated cells. Note that a 2D model was used whereas in reality stomata and droplets are elliptic and circular, respectively, and are distributed heterogeneously over the leaf surface which does not have a flat topology. Nevertheless, realistic coverage ratios and source sizes were evaluated in this study, which provides a first step in understanding the effect of such microscopic sources on convective transfer rates. To reduce the complexity of the computational model, the droplet thickness (volume) was not considered. In reality, the exposed surface area of a droplet can be larger than a flat area depending on the contact angle, and droplets obviously protrude into the laminar (viscous) sublayer, influencing the air flow in the boundary layer. This viscous sublayer is the lower part of the boundary layer, where laminar flow occurs. So, as a first approximation, the droplet is considered flat, either due to a low contact angle, or to a pinned droplet after some depletion by evaporation.

Due to the small scale of the computational cells at the surface $(10 \mu \mathrm{m})$, the validity of the analysis of gas transport with continuum models, based on Navier-Stokes equations with no-slip boundary conditions, has to be verified, since it is possible that molecular-dynamics based methods (e.g., Lattice Boltzmann) would be required [25-27]. This decision can be made based on the Knudsen number, which is defined as: $K n=\Lambda / L_{m}$, where $\Lambda$ is the mean free path length in air $\left(\approx 6.5 \times 10^{-8} \mathrm{~m}\right.$ at $1 \mathrm{~atm}, 20^{\circ} \mathrm{C}$ and $50 \%$ relative humidity; [28]) and $L_{m}$ is the characteristic flow dimension [m]. For $L_{m}$, the shear-layer thickness is appropriate for boundary layers [25]. For $K n<0.1$, the continuum hypothesis is valid, and for $K n<0.001$, the no-slip condition is valid [25]. The minimal laminar sublayer thickness in this study is $9.5 \times 10^{-5} \mathrm{~m}$ (see section 3.2.1), resulting in a Knudsen number of $6.9 \times 10^{-4}$, thus both criteria are satisfied. Even for the smallest length scale in the simulations (source size $d=10 \times 10^{-6} \mathrm{~m}$ ), the Knudsen number is still only $65 \times 10^{-4}$.

\section{Boundary-layer modelling}

The small scale of the cells at the leaf surface is the main reason for the high number of computational cells in the 2D computational model. Another reason is the way in which the flow in the boundary layer is modelled: instead of wall functions, which calculate the flow quantities in the boundary-layer region using semi-empirical functions [29], low Reynolds number modelling (LRNM) was applied, which explicitly resolves the transport in the boundary layer. However, at high Reynolds numbers, grids constructed to be employed with LRNM of the boundary layer require a 
high grid resolution (cell density) in the wall-normal direction: the $y^{+}$value in the wall-adjacent cell centre point $\mathrm{P}\left(y_{P}{ }^{+}\right)$ should be below 1 , whereas wall functions require $30<y_{P}{ }^{+}<500$. Here, $y_{P}{ }^{+}$is defined as $\left(\tau_{w} / \rho_{a}\right)^{1 / 2} y_{P} / v_{a}$, where $y_{P}$ is the distance (normal) from the cell centre point $\mathrm{P}$ of the wall-adjacent cell to the wall $\left(10 \times 10^{-6} \mathrm{~m}\right.$ in this study), $\rho_{a}$ is the air density $\left(1.225 \mathrm{~kg} \mathrm{~m}^{-3}\right.$ in this study), $v_{a}$ is the kinematic viscosity of air $\left(1.461 \times 10^{-5} \mathrm{~m}^{2} \mathrm{~s}^{-1}\right.$ in this study) and $\tau_{w}$ is the shear stress at the wall $[\mathrm{Pa}]$, which increases with the Reynolds number. The highest $y_{P}{ }^{+}$values are below 0.6 for all evaluated air speeds.

\subsubsection{Boundary conditions for air flow}

A developed momentum boundary-layer flow was imposed at the inlet of the computational domain, thus leading to a quasi-constant boundary-layer thickness over the leaf surface. The reason was that only the development of the scalar boundary layer by the microscopic scalar sources was of interest here, and, by the same token, the additional complexity of a developing momentum boundary layer was avoided. For the latter, laminar to turbulent transition occurs in addition, which is highly dependent on upstream flow conditions and air speed and is not straightforward to model accurately with CFD [22]. The authors are aware that a developed boundary layer is not representative for a single leaf in the field, but this configuration did allow to identify in a more systematic way the effect of discretely-distributed microscopic sources on scalar transport in the boundary layer, than would have been possible for a developing boundary layer. These boundary conditions also allowed a better comparison with analytical studies (see section 3.2.2).

Precursor simulations were performed (Figure 1a) to generate a developed velocity profile which was imposed at the inlet of the computational domain with the leaf described above (Figure 1b), as the aim was to only have scalar gradients for the leaf thus a constant momentum boundary-layer thickness. For the precursor simulations, isothermal flow in a two-dimensional, perfectly smooth channel was modelled (channel height $H=0.5 \mathrm{~m}$, channel length $=100 H$ ), where a uniform velocity was imposed at the inlet. Different bulk air speeds $\left(U_{b}\right)$ were evaluated, namely $0.02,0.2,2$ and $20 \mathrm{~m} \mathrm{~s}^{-1}$, resulting in Reynolds numbers based on the bulk speed $\left(U_{b}\right)$ and leaf length $(L)$ varying from 137 to $1.37 \mathrm{x}$ $10^{5}\left(R e_{b}=U_{b} L / v\right)$, thus including both laminar and turbulent flow. The turbulence intensity $\left(T I_{r e f}\right)$ at the inlet of the precursor domain was taken $0.1 \%$. The specific dissipation rate $\left(\omega\left[\mathrm{s}^{-1}\right]\right.$, required for the shear stress transport k- $\omega$ model, see section 2.2) was determined from $\omega=k^{1 / 2} /\left(C_{\mu}{ }^{1 / 4} L_{s}\right)$ [30], where $k$ is the turbulent kinetic energy $\left[\mathrm{m}^{2} \mathrm{~s}^{-2}\right], C_{\mu}=$ 0.09 and $L_{s}$ is a length scale which is taken small (arbitrarily) and equal to $H / 500(0.001 \mathrm{~m})$. The numerical simulation settings were identical in both the precursor and the leaf simulations(see section 2.2 for details). The velocity and turbulence profiles ( $k$ and $\omega$ ) at the precursor outlet were extracted and were used as inlet conditions for the simulations with the leaf (Figure 1b). These profiles were found to remain quasi constant throughout the leaf domain, indicating that the flow was sufficiently developed.

Apart from this inlet profile, zero static pressure was imposed at the outlet, which is advised in best practice guidelines (e.g., [23]). A symmetry boundary condition was used for the upper boundary which assumes that the normal velocity component and the normal gradients at the boundary are zero. The leaf surface and channel walls were modelled as no-slip walls with zero roughness since surface roughness values cannot be specified when LRNM is used [30]. Surface roughness may however enhance scalar transfer rates and alter the flow field around the leaf.

\subsubsection{Boundary conditions for scalar transfer}


Calculating turbulent water vapour transport from the leaf surface would imply solving following equation:

$$
\frac{\partial \rho_{g} x_{v}}{\partial t}+\nabla \cdot\left(\rho_{g} x_{v} \mathbf{v}\right)=\nabla \cdot\left(\rho_{g} D_{v a, e f f} \nabla x_{v}\right)
$$

where $x_{v}$ is the mass fraction of water vapour in the air $\left[\mathrm{kg}_{\mathrm{v}} \mathrm{kg}_{\mathrm{g}}{ }^{-1}\right]$, the subscript $\mathrm{g}$ refers to the mixture air, which consists of dry air (subscript a) and water vapour (subscript v), $\mathbf{v}$ is the air velocity vector $\left[\mathrm{m} \mathrm{s}^{-1}\right]$ and $D_{v a, e f f}$ represents the effective diffusion coefficient of water vapour in (dry) air $\left[\mathrm{m}^{2} \mathrm{~s}^{-1}\right]$, which is defined as the sum of the molecular diffusion coefficient $\left(D_{v a}\right)$ and the turbulent diffusion coefficient $\left(D_{v a, t}\right)$ :

$$
D_{v a, e f f}=D_{v a}+D_{v a, t}=D_{v a}+\frac{\mu_{t}}{\rho_{g} S c_{t}}
$$

where $S c_{t}$ is the turbulent Schmidt number and $\mu_{t}$ is the turbulent viscosity $\left[\mathrm{kg} \mathrm{m}^{-1} \mathrm{~s}^{-1}\right]$. In the water vapour transfer equation, the air properties (e.g., density), thus the air flow, are inherently a function of the water vapour mass fraction in the air and of the temperature (e.g., saturation vapour pressure at the surface), which in principle requires solving the flow, turbulence and heat transport equations in every simulation.

However, the computational cost to evaluate different scalar boundary conditions (see section 3.2.2) can be decreased significantly by considering transport of another (passive) scalar, instead of mass (i.e., water vapour), where passive indicates that the scalar does not influence the flow field. For such passive scalar transfer, the flow field has to be solved only once for each air speed, since the air properties (e.g., density) can be taken constant in this case, by which only the scalar field has to be recalculated for the different imposed scalar boundary conditions, i.e., coverage ratios of the microscopic sources. As such, solving the air flow and turbulence equations could be disabled, by which different scalar boundary conditions could be evaluated more quickly. In addition, when solving for mass fraction (Eq. (1)), a constant concentration boundary condition could only be imposed at the wall in the software that was used, whereas it will be shown below that a flux condition is required for this study.

Thereto, heat was taken as the passive scalar to study convective transport, amongst others since it also allowed a straightforward and physical interpretation of the scalar transfer, e.g., in terms of convective heat transfer coefficient (CHTC) or Nusselt number. This implies, amongst others, that only dry air is considered (subscript a) and also no dependency of air density on the temperature, since heat is considered as a passive scalar. The following heat (scalar) transfer equation is solved when buoyancy and viscous dissipation of heat are not taken into account and incompressible flow is assumed:

$$
\frac{\partial \rho_{a} c_{a} T}{\partial t}+\nabla \cdot\left(\rho_{a} c_{a} T \mathbf{v}\right)=\nabla \cdot\left(\lambda_{e f f} \nabla T\right)
$$

where $T$ is the temperature and $\lambda_{\text {eff }}$ represents the effective thermal conductivity of the air, which is defined as the sum of the molecular thermal conductivity of air $\left(\lambda_{a}, 0.0242 \mathrm{~W} \mathrm{~m}^{-1} \mathrm{~K}^{-1}\right)$ and the turbulent thermal conductivity $\left(\lambda_{t}\right)$ :

$$
\lambda_{\text {eff }}=\lambda_{a}+\lambda_{t}=\lambda_{a}+\frac{c_{a} \mu_{t}}{\operatorname{Pr}_{t}}
$$

where $P r_{t}$ is the turbulent Prandtl number ( 0.85 in this study). The turbulent thermal conductivity accounts for the influence of turbulence on the scalar transport and is proportional to $\mu_{t}$, which is calculated by the used turbulence model. The specific heat capacity of air $\left(c_{a}\right)$ was taken $1006.43 \mathrm{~J} \mathrm{~kg}^{-1} \mathrm{~K}^{-1}$. All air properties are assumed constant. 
After solving heat transport, convective mass transfer coefficients (CMTC) can be estimated out of CHTC data using the heat and mass transfer analogy (e.g., [31]). These convective transfer coefficients (CTCs) relate the convective heat and moisture flux normal to the wall $\left(q_{c, w}\left[\mathrm{~J} \mathrm{~s}^{-1} \mathrm{~m}^{-2}\right]\right.$ and $\left.g_{v, w}\left[\mathrm{~kg} \mathrm{~s}^{-1} \mathrm{~m}^{-2}\right]\right)$, i.e., at the air-material interface, to the difference between the wall temperature $\left(T_{w}\left[{ }^{\circ} \mathrm{C}\right.\right.$ or $\left.\left.\mathrm{K}\right]\right)$ or water vapour pressure at the wall $\left(p_{v, w}[\mathrm{~Pa}]\right)$ and a reference temperature $\left(T_{r e f}\left[{ }^{\circ} \mathrm{C}\right.\right.$ or $\left.\left.\mathrm{K}\right]\right)$ or vapour pressure $\left(p_{v, r e f}[\mathrm{~Pa}]\right)$, which can be taken, for example, equal to the approach flow conditions:

$$
\begin{aligned}
& C H T C=\frac{q_{c, w}}{T_{w}-T_{r e f}} \\
& C M T C=\frac{g_{c, w}}{p_{v, w}-p_{v, r e f}}
\end{aligned}
$$

The fluxes are assumed positive away from the leaf surface.

The conditions under which the analogy is valid are, amongst others, similar boundary conditions, no radiation, no coupling between heat transfer and the other scalar, etc. (see [31-32]), and were applied in the present study. As such, the general analogy equation [33] can be rewritten to the CMTC [31]:

$$
C M T C=\frac{1}{R_{v} T_{w}\left(\rho_{a} c_{a}\right)^{1 / 3}}\left(\frac{D_{v a}}{\lambda_{a}}\right)^{2 / 3} C H T C
$$

where $R_{v}$ is the specific gas constant of water vapour $\left(461.524 \mathrm{~J} \mathrm{~kg}^{-1} \mathrm{~K}^{-1}\right)$.

The validity of this analogy was verified for turbulent flow and also for Lewis numbers which are not equal to one [34]. As the diffusivity of heat and water vapour in air are quite similar, the Lewis number is almost equal to one $(\approx$ 0.8), by which their boundary-layer development will also be similar. To demonstrate the validity of using heat transfer in combination with the analogy to study water vapour transport from leaves, instead of water vapour itself, numerical solutions of both methods are compared in Appendix 2. It is shown that solving for water vapour (Eq. (1)) or heat transfer (Eq. (3)) gives very similar CMTC results, i.e., with the difference of only $1.4 \%$. As such, the reported results are generally useable, i.e., they are also applicable for transport of other scalars, such as water vapour, $\mathrm{O}_{2}$ or $\mathrm{CO}_{2}$. Therefore, the terms scalar transfer and scalar flux will be mainly used in the remainder of the paper instead of heat transfer and heat flux in the discussion of the results, as the findings hold for any passive scalar which obeys Eqs. (3)(4). The imposed thermal boundary conditions in the computational domain are specified in detail below.

A temperature of $10^{\circ} \mathrm{C}\left(T_{r e f}\right)$ was imposed at the inlet of the computational domain. A no-flux condition was imposed at the channel walls. To model the heterogeneous boundary conditions at the leaf surface (discretelydistributed scalar sources), a specific type of scalar boundary condition was imposed: a constant wall temperature $\left(T_{w}=\right.$ $20^{\circ} \mathrm{C}$ ) was imposed at discrete locations on the leaf surface, i.e., at the computational cells which were sources; the rest of the surface was assumed impermeable for heat (no-flux condition for scalar), i.e., adiabatic, thus for this part of the surface a zero wall-normal scalar gradient was present in the wall-adjacent cells. This boundary condition accounts for discretely-distributed scalar sources on the leaf surface and is representative for convective vapour exchange at stomata 
or droplets: at these locations, a constant scalar value (e.g., water vapour pressure) is found and scalar transfer occurs, whereas (quasi) no scalar transfer from/to the surface is possible in the other parts (i.e., via the cuticle). This type of boundary condition was implemented in the software by means of a user-defined function. This boundary condition is simplified in the sense that all sources (stomata/droplets) are assumed to be at the same scalar potential (e.g., temperature or vapour pressure), and an interaction with the transport inside the leaf (from substomatal cavities via stomata) is not accounted for.

Three different source sizes $(d)$ were evaluated: (1) $10 \mu \mathrm{m}$, representing small, or semi-closed stomata; (2) $50 \mu \mathrm{m}$, representing large or fully-open stomata, or small droplets; (3) $250 \mu \mathrm{m}$, representing larger droplets. To model source sizes larger than the size of the individual cells at the surface $(10 \mu \mathrm{m})$, different adjacent cells were given the same boundary condition, i.e., a constant scalar potential, leading to 5 and 25 grouped, adjacent cells for source sizes of 50 $\mu \mathrm{m}$ and $250 \mu \mathrm{m}$, respectively. For each of these source sizes, different coverage ratios (CR) were evaluated, namely $0.2 \%, 1 \%, 5 \%, 10 \%, 20 \%, 40 \%, 60 \%, 80 \%$ and $100 \%$. The coverage ratio is defined as the ratio of the area occupied by the sources $\left(A_{\text {eff }}\left[\mathrm{m}^{2}\right]\right)$ to the total leaf area $\left(A\left[\mathrm{~m}^{2}\right]\right)$, i.e., $\mathrm{CR}=A_{\text {eff }} / A$. A coverage ratio of $100 \%$ corresponds to a uniform scalar potential at the entire leaf surface (i.e., $T_{w}=20^{\circ} \mathrm{C}$ ). This boundary condition was often used in literature for flat plates to determine correlations of CTCs with the air speed. Note that stomata always have a very low coverage ratio, ranging from about $0.2 \%$ to $5 \%$ for open stomata [1,21,35].

\subsection{Numerical simulation}

The CFD simulations were performed with the commercial code ANSYS Fluent 13, which uses the control volume method. The accuracy of CFD simulations depends to a large extent on the turbulence-modelling and boundary-layer modelling approaches that are used, which have to be quantified by means of validation experiments/simulations. In this study, steady Reynolds-averaged Navier-Stokes (RANS) was used in combination with the shear stress transport (SST) k- $\omega$ model [36]. LRNM was applied to resolve the transport in the boundary-layer region. LRNM was actually included in the SST k- $\omega$ model [30], i.e., the SST k- $\omega$ model was used as a LRNM model and did not require additional damping functions in the vicinity of the wall. In the past, the good performance of this RANS turbulence model combined with LRNM was already demonstrated for several complex flow problems (e.g., [37-39]). For simple flow problems, as the one considered in this study, this turbulence model was thus considered sufficiently accurate, and no additional validation was performed. The developed turbulent velocity profiles agreed well with the universal law-of-the-wall profile for boundary layers (e.g., [40]), including the logarithmic-law region (results not reported).

Furthermore, second-order discretisation schemes were used throughout. The SIMPLE algorithm was used for pressure-velocity coupling. Pressure interpolation was second order. A double-precision solver was required due to the very large range of spatial scales in the computational domain. Buoyancy effects and radiation were not taken into account in the simulations since the focus was on the transport of a general passive scalar, where these terms do not appear in the transport equation. This implies forced convective flow and the validity of the heat and mass transfer analogy. Iterative convergence of the numerical simulation was assessed by monitoring the velocity, turbulent kinetic energy and temperature at the outlet, and the drag force and heat fluxes at the leaf surface. Especially at low coverage ratios and low Reynolds numbers, the convergence behaviour of the scalar was quite slow. 


\section{$\underline{\text { 3. Results }}$}

\section{$\underline{3.1 \text { Background }}$}

A brief background is given on the impact of heterogeneous boundary conditions (i.e., scalar sources) on the resulting convective scalar transfer, compared to homogeneous (uniform) boundary conditions. For such uniform scalar boundary conditions (e.g., constant wall temperature), the CHTC or CMTC of the leaf (Eqs. (5)-(6)) can also be written as:

$$
\begin{gathered}
C H T C=\frac{Q_{c, w, a v g}}{A\left(T_{w}-T_{r e f}\right)} \\
C M T C=\frac{G_{c, w, a v g}}{A\left(p_{v, w}-p_{v, r e f}\right)}
\end{gathered}
$$

where $Q_{c, w, \text { avg }}\left[\mathrm{J} \mathrm{s}^{-1}\right]$ and $G_{c, w, \text { avg }}\left[\mathrm{kg} \mathrm{s}^{-1}\right]$ are the surface-averaged heat and vapour flows and $A\left[\mathrm{~m}^{2}\right]$ is the leaf area. Such boundary conditions are not realistic for leaf transpiration via stomata or for droplet evaporation from leaf surfaces: (scalar) transfer occurs here only at specific parts of the leaf surface $\left(A_{e f f}\right)$, namely at microscopic scalar sources which are distributed heterogeneously, but not over the entire surface $(A)$.

Previous research indicated that the scalar flows (e.g., $G_{c, w, a v g}$ ), and thus the CTCs, do not scale linearly with this reduced area for scalar transfer $\left(A_{e f f}\right)$ : Schlünder [20] showed analytically that, for a laminar boundary-layer flow over a flat surface, under specific conditions, a high mass transfer rate could be maintained for a partially-wetted surface, by which the surface behaves actually very similar to a uniformly-wetted surface. These conditions are that the characteristic size of the wetted areas $(d)$ on the surface (called sources, i.e., stomata or droplets in this study) is small compared to the thickness of the viscous sublayer $\delta_{V S L}$ (i.e., the lower part of the boundary layer where laminar transport occurs and where large velocity and temperature gradients are found; e.g., [37]; [m]), and that these sources are homogeneously distributed on the surface. In this case, the concentration contours quickly equalise in the wall-normal direction (become parallel to the wall) away from the sources (Figure 3a). As such, the saturation vapour pressure is found above quasi the entire surface, and not only directly above the wet sources [20]. Thereby, the surface appears to be quasi completely wet for the flow, i.e., a quasi-uniform vapour pressure is found along a horizontal line within the viscous sublayer. This vapour pressure is very close to the saturation vapour pressure. This results in a high mass transfer rate, even for a reduced wet surface area [20,41-42]. The analytical expression derived by Schlünder [20] for droplets is as follows:

$$
\frac{G_{c, w, C R}}{G_{c, w, 100 \%}}=\frac{1}{1+\Phi}
$$

with $\Phi=\frac{2}{\pi} \frac{r}{\delta_{V S L}} \sqrt{\frac{\pi}{4 C R}}\left(\sqrt{\frac{\pi}{4 C R}}-1\right)$

where $\mathrm{r}$ is the radius of the droplets, $\mathrm{CR}$ is the surface coverage ratio $\left(\mathrm{CR}=A_{e f f} / A\right)$, and $G_{c, w, C R}$ and $G_{c, w, 100 \%}$ are the mass flows at the surface (normal to the wall) at a specific coverage ratio $\mathrm{CR}$ and at $\mathrm{CR}=100 \%$, respectively. This equation is only useable for $\mathrm{CR} \leq \pi / 4$, since otherwise $\Phi$ becomes negative, leading to $G_{c, w, C R}>G_{c, w, 100 \%}$. Note that Schlünder [20] assumed only laminar transport in the boundary layer, by which the viscous sublayer thickness $\left(\delta_{V S L}\right)$ was equal to 
the entire boundary layer thickness. Since Eqs. (10)-(11) will be reported in the remainder of the paper as a function of the CR and the $d / \delta_{V S L}$ ratio, the characteristic size of the sources $(d)$ needs to be defined in Eqs. (10)-(11). The radius of the droplet $(r)$ could be taken as the characteristic size of the sources $(d)$ in Eq. (11), as was done by Defraeye et al. [39] when reporting Eqs. (10)-(11) as a function of the $d / \delta_{V S L}$ ratio. However, in the present study, $d$ was taken equal to $2 r$ when reporting Eqs. (10)-(11) and the corresponding $d / \delta_{V S L}$ ratios, amongst others as it seemed more appropriate for the 2D case under study. The choice of $d$ in Eq. (11) is however not very critical since it will be shown below that the $\delta_{V S L}$ for turbulent flow is defined rather arbitrary. Schlünder's expression is evaluated in Figure $3 \mathrm{~b}$ for different $d / \delta_{V S L}$ ratios (with $d=2 r$ ). The $d / \delta_{V S L}$ ratio can also be called the microscopic Sherwood number [20]. Low $d / \delta_{V S L}$ ratios show high transfer rates, even at very low surface coverage ratios [20].

For (turbulent) boundary layers, $\delta_{V S L}$ is defined in this study as the region where $y^{+}<5$, which is approximately the upper $y^{+}$limit of the viscous sublayer in turbulent boundary layers (e.g., [43]). From the definition of $y^{+}$, (section 2.1.2) this results in:

$$
\delta_{V S L}=\frac{5 v_{a}}{\sqrt{\frac{\tau_{\mathrm{w}}}{\rho_{a}}}}
$$

$\delta_{V S L}$ is thus inversely proportional to the square root of the shear stress at the wall. As the shear stress increases with the air speed $\left(U_{b}\right)$, the boundary-layer thickness (thus also $\delta_{V S L}$ ) will decrease. Although heat transfer was solved for in this study, the CMTCs can be determined by means of the analogy (Eq.(7)), as shown in section 2.1.4. However, the results will be presented in dimensionless form, by which such a conversion is not even required.

\subsection{Convective scalar transfer at the leaf surface}

\subsubsection{Uniform coverage}

Prior to investigating the effect of partial coverage of the leaf surface, flow and scalar transfer for a uniform coverage (CR 100\%) are evaluated. In Figure 4 , the average boundary-layer thickness over the leaf surface $\left(\delta_{V S L, \text { avg }}\right)$ is shown as a function of the bulk Reynolds number $\left(R e_{b}\right)$, which varies between $0.04 \mathrm{~m}$ and $10^{-4} \mathrm{~m}$. Note that the boundary-layer thickness was quasi constant over the leaf surface due to the developed velocity profile (standard deviation below $0.1 \%$ ). According to Dean [44], flow in two-dimensional channels remains laminar up to channel Reynolds numbers $\left(R e_{c}=U_{b} H / v\right)$ of about 1300. In this study, $R e_{c}$ varied from 685 to $6.85 \times 10^{5}$, by which the flow was laminar at only one air speed $\left(U_{b}=0.02 \mathrm{~m} \mathrm{~s}^{-1}\right)$, which was confirmed by the velocity profiles. In addition, the microscopic Sherwood numbers $\left(d / \delta_{V S L, a v g}\right)$ are given in Figure 4 for different source sizes, as well as the surfaceaveraged scalar (heat) flux over the leaf $\left(q_{c, w, a v g, 100 \%}\right)$, which varies between $10 \mathrm{~W} \mathrm{~m}^{-2}$ and $834 \mathrm{~W} \mathrm{~m}^{-2}$. In Figure 5 , the local scalar flux distribution over the leaf surface (CR 100\%, $\left.q_{c, w, 100 \%}\right)$, scaled with $q_{c, w, a v g, 100 \%}$, is shown at different Reynolds numbers as a function of the distance from the leading edge $(x / L)$. Although the distributions are similar, i.e., high values at the leading edge due to the scalar boundary-layer development, the gradients with $x / L$ are smaller at low speeds. For laminar flow, a clear increase in flux is found towards the end of the leaf. This increase is due to an edge effect at the trailing edge: the scalar concentration contours are not parallel to the leaf surface anymore at the trailing edge but become rather curved (rounded) due to the absence of a scalar source downstream from the trailing edge, which leads to an increased scalar transfer here. This effect manifests itself upstream of the trailing edge, particularly at 
low air speeds. Note that the scalar flux is directly proportional to the convective transfer coefficient (CTC) (Eqs. (5)(6)), due to the imposed constant scalar potential difference $\left(T_{w}-T_{r e f}\right)$.

\subsubsection{Partial coverage}

\section{Total scalar flow from surface}

The impact of a reduced area for scalar transfer, i.e., only at discretely-distributed microscopic scalar sources, on the convective transfer from the leaf surface is investigated. In Figure 6, the scalar concentration contours (i.e., of temperature) are shown at the leading edge of the leaf for different air speeds and different source sizes for a coverage ratio of $5 \%$ (a total of 30 contours over a temperature range from $10-20^{\circ} \mathrm{C}$ ). For each source size, the scalar boundarylayer thickness decreases with increasing air speed. At low speeds, the contours look more symmetrical on both sides of the sources, but at higher speeds, the scalar is convected more downstream and a wake zone can be noticed.

The surface-averaged convective scalar flows $\left(Q_{c, w, a v g}\right)$ from the leaf are shown in Figure 7 as a function of the coverage ratio for the three source sizes separately. For each source size $(d)$, results at different air speeds $\left(U_{b}\right)$, thus $d / \delta_{V S L}$ ratios, are presented. These scalar flows are scaled with the surface-averaged scalar flow for a coverage ratio of $100 \%\left(Q_{c, w, a v g, 100 \%}\right)$. The analytical solutions of Schlünder (Eqs. (10)-(11), laminar flow) for the corresponding microscopic Sherwood numbers $\left(d / \delta_{V S L}\right)$ are also presented. A focus of the region CR $=0-10 \%$ is also shown, as large gradients with coverage ratio are found here, and as only this region is relevant for stomata due to their low density (CR) of only a few percent. The same CFD results are presented in Figure 8, but now different source sizes are grouped together for each air speed $\left(U_{b}\right)$ separately. These scalar flows are directly proportional to the convective transfer coefficient of the leaf (CTC), when defined according to Eqs. (8)-(9).

From Figure 7, relatively high scalar flows at the surface are found at low coverage ratios (for all $d / \delta_{V S L}$ ratios and source sizes), thus they clearly do not vary linearly with the coverage ratio. This effect is more pronounced at low microscopic Sherwood numbers $\left(d / \delta_{V S L}\right)$, implying low air speeds (Figure 7) or small source sizes (Figure 8), which is similar to the findings of Schlünder [20] for laminar flow over a flat plate. The agreement between the CFD simulation results and the analytical solutions seems better for low $d / \delta_{V S L}$ ratios. Differences exist however, even for laminar flow

$\left(U_{b}=0.02 \mathrm{~m} \mathrm{~s}^{-1}\right)$, where the analytical solutions seem to systematically predict higher transfer rates, particularly at low coverage ratios. Possible reasons for these mismatches are that: (1) for the flat plate of Schlünder [20], the boundary layer was assumed to be developed thus under equilibrium conditions whereas, on the leaf surface, the thermal boundary layer was still strongly developing, with a clear leading-edge effect; (2) in this study, channel flow was considered, instead of flat-plate flow, but this effect is considered limited due to the large height of the channel; (3) the viscous sublayer thickness defined in this study $\left(\delta_{V S L}\right)$, i.e., derived based on turbulent boundary layers (Eq. (12)), is different from the one of Schlünder, as the latter assumed that only a viscous sublayer was present in between the surface and the free-stream flow; (4) turbulent flow was also considered in this study, compared to only laminar flow by Schlunder.

When the aforementioned results are grouped together for all microscopic Sherwood numbers $\left(d / \delta_{V S L}\right)$ in Figure 9, a strong correlation between the scalar flow from the leaf and the microscopic Sherwood number is identified: for a certain coverage ratio, the scalar flow always increases with decreasing $d / \delta_{V S L}$ ratio, irrespective of the specific source 
size or air speed at which it was evaluated. An exception is found at $d / \delta_{V S L}=0.009$ where the scalar flow is found to be slightly higher than at $d / \delta_{V S L}=0.006$.

At low microscopic Sherwood numbers $\left(d / \delta_{V S L}\right)$, relatively high scalar flows at the surface are found, but, at high microscopic Sherwood numbers, scalar flows decrease significantly with decreasing coverage ratio. These findings have an impact on the use of well-established convective transfer coefficients from plates or leaf models, and their correlations with the air speed, which were determined using homogeneous boundary conditions (CR 100\%): although they seem rather acceptable for low $d / \delta_{V S L}$ ratios, these boundary conditions and corresponding CTCs can result in a significant overprediction of the convective exchange for high $d / \delta_{V S L}$ ratios, compared to the actual heterogeneous boundary conditions (i.e., microscopic scalar sources). This effect is especially manifested at low surface coverage ratios (Figure 7), thus relevant for stomata, which always have a very low coverage ratio ( $0.2 \%-5 \%$, see section 2.1 .4$)$. From the present study, the CMTC of a leaf with stomata $($ size $=10 \mu \mathrm{m})$ with a coverage ratio of $1 \%$ can decrease down to $16 \%$ of that of a leaf with a coverage ratio of $100 \%$ at high air speeds (see Figure 7). Such a mismatch between CMTCs for fully-covered and partially-covered conditions can strongly compromise the accuracy of convective exchange predictions.

Furthermore, the largest decrease (or gradient) in scalar flows with coverage ratio was found at low coverage ratios, particularly for low microscopic Sherwood numbers $\left(d / \delta_{V S L}\right)$, i.e., small source sizes and low air speeds. These conditions are thus relevant for stomata, which always have a low coverage ratio $(0.2 \%-5 \%)$ and a small size (few tens of microns, see section 1). As such, small variations in stomatal density on the leaf surface, e.g., due to biological variability, will have a large impact on the convective exchange (thus on the CMTC): from the present study, the CMTC of a leaf with stomata (size $=10 \mu \mathrm{m}, \mathrm{CR}=0.2 \%-5 \%$ ) at a Reynolds number of $1370\left(U_{b}=0.2 \mathrm{~m} \mathrm{~s}^{-1}\right)$ will vary between $35 \%-96 \%$ of that of a leaf with a coverage ratio of $100 \%$ (see Figure 7).

\section{$\underline{\text { Local scalar fluxes at sources }}$}

The scalar flows clearly do not scale linearly with the reduced surface area for scalar transfer (Figure 7). As such, the local fluxes at the sources $\left(q_{c, w}\right)$ are higher at decreasing coverage ratios. In Figure 10, this local flux increase is indicated by presenting the effective scalar flux $\left(q_{c, w, a v g, e f f}\right)$, averaged only over the sources on the leaf (thus over $A_{\text {eff }}$ ), as a function of the coverage ratio. These fluxes are scaled with the surface-averaged flux for a leaf with a uniform coverage $\left(q_{c, w, a v g, 100 \%}\right)$. At low coverage ratios, the fluxes increase even with a factor 10 or more, particularly at low microscopic Sherwood numbers. Leclerc et al. [45] also reported a local increase in fluxes at the sources from experiments. This implies that droplets of a certain size will evaporate more rapidly from leaf surfaces at low coverage ratios.

\section{$\underline{\text { 3.2.3 Stomatal aperture }}$}

The impact of stomatal aperture can be assessed by considering the scalar flows of two leaves with the same number of stomata (i.e., 100), located at the same position on the leaf surface, but with different source sizes: $10 \mu \mathrm{m}$ (at CR $1 \%$ ), representing semi-closed stomata, and $50 \mu \mathrm{m}$ (at CR 5\%), representing fully-open stomata. In Figure 11, the surface-averaged convective scalar flows from the leaf $\left(Q_{c, w, a v g}\right)$ are given as a function of the bulk Reynolds number for both states of stomatal aperture, scaled with $Q_{c, w, a v g, 100 \%}$, which is the same for these two states A clear decrease in 
transfer rate is found when stomata close, indicating that stomatal aperture has a large impact on the convective exchange (thus on the CMTC). The difference becomes higher for high air speeds, as the microscopic Sherwood number increases. Note that, despite the lower total transfer rate for semi-closed stomata, the local fluxes are still higher than for fully-open stomata (see section 3.2.2), by which the reduction in transfer rate for semi-closed stomata $\left(Q_{c, w, a v g}\right)$ is not proportional to the reduction in coverage ratio, as discussed in the previous sections.

\section{Discussion}

In this study, an innovative microscale computational modelling framework was presented to investigate convective water vapour transfer from leaf surfaces via stomata and droplets. Although an important first step was taken in this modelling approach, by which new insights in these exchange processes were obtained, the model and modelling strategy could be improved. Thereto, focus points for future research are identified and discussed in this section.

\subsection{Conjugate modelling and boundary conditions}

This study focussed on the air-side convective mass (passive scalar) transport from leaf surfaces. In reality, mass (and heat) transport inside the leaf also affect the exchange processes, thus actually the conjugate transfer problem, including transport in both air and leaf, should be considered, as well as its impact on the boundary conditions at the leaf-air interface. Some of these aspects are highlighted below.

In the work presented here, the convective transfer of a single scalar was considered, representative for water vapour. However the evaporation of droplets or transpiration via stomata is inherently coupled, to some extent, to convective heat transfer and vice versa, due to the (saturation) vapour pressure and the latent heat of vaporisation. Nevertheless, for low evaporation/transpiration rates, a quasi-isothermal state will be induced, by which this coupling is quite weak and both transfer mechanisms can be considered quasi uncoupled.

For droplets, the evaporation kinetics are quasi entirely determined by the convective exchange processes, but for leaves, the transpiration rate is also determined by the water vapour transport from the cellular tissue (relative humidity $\approx 100 \%$; [1]) to the substomatal cavities and through the stomata. Particularly the stomatal resistance can be quite large [1], and is regulated by the stomatal aperture. Due to the variation in mass boundary-layer thickness (resistance) and stomatal resistance across the leaf, the concentration at the surfaces of individual stomata can differ, whereas, in this study, a constant concentration was assumed for all stomata.

Due to the coupling of convective (air-side) mass and heat transfer with the transport within the leaf, the commonly imposed boundary conditions on the leaf surface to predict CTCs for leaves (e.g., uniform scalar) are thus always simplifications of reality, which are also often applied in experiments. A coupled-conjugate numerical modelling approach would be more appropriate, where both the heat and mass transport processes (coupled) in both the air and the leaf are solved simultaneously. Recently, Defraeye et al. [31] showed that using a conjugate approach could clearly increase the accuracy of convective exchange predictions in some cases, whereas in other cases, no significant increase in accuracy was found. The sensitivity to conjugate modelling was rather low for cases where the resistance to transfer within the material (e.g., the leaf) was relatively high, compared to that of the boundary layer. So despite the recent 
efforts towards conjugate modelling of coupled heat and mass transport, its relevance here could be questioned and should be verified more in detail.

In this study, the leaf boundary-layer resistance was very low at high air flow rates, by which the transpiration rate will be mainly controlled by the resistance within the leaf. In this case, a reduced accuracy of convective transfer predictions (i.e., CMTCs) does not compromise a reliable calculation of the transpiration rate. Hence, simplified CMTC predictions, based on flat plates with uniform boundary conditions, could be acceptable. Accurate convective transfer predictions are thus most relevant at low air speeds (i.e., low CMTCs). To identify the relevance for leaves more in detail, future steps should be taken towards conjugate modelling, for example by including a resistance model for the substomatal cavities and the stomata in the present numerical model.

Finally, with respect to the momentum boundary conditions imposed at the leaf-air interface, there is a difference between droplets and stomata. For droplet evaporation, a water vapour flow from the surface is present which will induce a net convective (vapour) flow into the air, in addition to diffusion. For stomata on the other hand, the water vapour flow through the interface, via the stomata, will be compensated by an opposite flow of other components $\left(\mathrm{O}_{2}\right.$, $\mathrm{CO}_{2}, \mathrm{~N}_{2}$ ), resulting in no net convective flow through the interface. The latter is in agreement with the boundary conditions imposed in the present study, where no influence of scalar transfer on the air (momentum) flow was assumed. Although this convective flow induced by droplets is considered to be limited, its impact can be clarified more in detail by including momentum source terms at the interface in the present numerical model.

\subsection{Full-scale vs. multiscale modelling}

A very large range of spatial scales was included in the computational model $\left(10^{-5} \mathrm{~m}\right.$ to $\left.10^{-1} \mathrm{~m}\right)$, which is exceptional for a numerical study. Although very useful for increasing our understanding in transport phenomena across scales, the applied full-scale modelling approach is often not practically feasible for complex 3D flow systems (e.g., an entire plant) due to the high computational expense and the challenging grid generation. Instead, the multiscale modelling paradigm is often applied (e.g., [46-47]). Multiscale modelling could also provide an outcome here, but the inherent problem of coupling between the scales remains present, and should be explored more in detail.

\subsection{Assumptions}

The assumptions made in this numerical study should be acknowledged, to fully appreciate its added value to the existing knowledge on convective transfer phenomena for leaves, and to identify what future developments and refinements of the model could imply. First, the leaf was subjected to a developed flow in order to have a constant momentum boundary-layer thickness over the surface. In reality however, a leaf is a freestanding surface with strong boundary-layer development. In addition, the flow conditions also differed from the natural environment of horticultural crops or trees, e.g., in a greenhouse or orchard. Such conditions can however easily be investigated with the computational model. Second, a two-dimensional study was performed, whereas in reality, three-dimensional flow is present, including edge effects. Furthermore, the distribution of the sources across the leaf is also different in 3D, as they are not located anymore directly downstream of one another. Third, buoyancy was not modelled, as the focus was on forced-convective (passive) scalar transport. Another assumption was that radiation was not taken into account in the model. Also, no coupling between heat and mass transfer was accounted for. Only air-side transfer was considered and 
transfer inside the leaf was not, implying non-conjugate modelling. Furthermore, surface roughness could not be accounted for due to the use of LRNM for modelling transport in the boundary layer. In addition, the thickness (hence volume) of droplets was not considered, to reduce the complexity of the computational model. Finally, the convective flow induced by droplet evaporation was not accounted for. Despite these assumptions, the present computational model already provided new insights in the exchange processes at the microscale, and the discussion in this section indicated how this modelling framework could be extended in the future.

\section{$\underline{\text { 5. Conclusions }}$}

Convective mass exchange at leaf surfaces was investigated from the perspective of leaf transpiration via stomata or evaporation of small droplets. These moisture sources are of microscopic scale and are heterogeneously distributed across the leaf surface, implying a reduced area for vapour transfer. Since an experimental analysis of convective transport from these individual sources at microscale level was very challenging, another approach was explored, namely numerical modelling of the air-side transport by means of computational fluid dynamics. A two-dimensional full-scale modelling approach was used, where both the microscopic sources $\left(10^{-5} \mathrm{~m}\right)$ as well as the entire leaf $\left(10^{-1} \mathrm{~m}\right)$ were included. The novelty of this approach lies in the fact that a very large spatial range is covered, where the convective transfer rate could be quantified down to the stomatal level.

The convective exchange was shown to be strongly dependent on three parameters: surface coverage, air speed (Reynolds number) and source size, and the same trends were observed as with existing analytical expressions. At low microscopic Sherwood numbers, i.e. the ratio of the source size to the viscous sublayer thickness, relatively high mass flows from the leaf could be found even at very low surface coverage ratios (CR). At high microscopic Sherwood numbers however, the decrease of the mass flows with decreasing coverage ratio was already pronounced at high CR. This implies that convective transfer coefficients obtained from well-established convective transfer research on plates or leaf models using homogeneous boundary conditions (CR 100\%) can result in a significant overprediction of the convective exchange, compared to the actual heterogeneous boundary conditions (microscopic sources).

At very low coverage ratios, e.g., representative for stomata, a large variation of the transfer rate with coverage ratio could be found. This implies that small variations in stomatal density on the leaf surface, e.g. due to biological variability, will have a large impact on the convective mass exchange rate. Furthermore, the local fluxes at the sources were found to increase with decreasing coverage ratio, which implies that droplets will evaporate more rapidly from leaf surfaces at low coverage ratios. The decrease in transfer rate due to stomatal closure was also quantified, indicating that the stomatal aperture has a large impact on the convective exchange, thus on the convective mass transfer coefficients.

In this study, a step towards a better insight in convective exchange processes at stomata and small droplets was taken by means of two-dimensional numerical modelling, namely by accounting for the microscale level. The modelling assumptions and limitations were clearly identified, and allowed to define focus points for future model refinement as well as future research. This includes, amongst others, three-dimensional modelling of leaves in more realistic environments, including modelling of coupled heat and mass transfer in a conjugate way, i.e. solving transport both in 
Defraeye T., Verboven P., Derome D., Carmeliet J., Nicolai B., Stomatal transpiration and droplet evaporation on leaf surfaces by a microscale modelling approach, International Journal of Heat and Mass Transfer 65, 180-191. http://dx.doi.org/10.1016/j.ijheatmasstransfer.2013.05.075

the air and the leaf simultaneously. Furthermore, multiscale modelling could be pursued to upscale the findings of the present study to larger scales. The added value of computational modelling will become even more pronounced when considering such complex problems. Compared to experiments, numerical modelling is especially recommended if the boundary-layer microclimate and the transport therein is of interest, such as for the analysis of the complex stomatal regulatory mechanism, contamination of leaves by pathogens, or the evaporation kinetics of pesticide droplets. Though experiments can be devised to confirm or complement the findings of the present study with respect to the impact of microscopic sources on convective transfer at the leaf surface, an experimental assessment of the boundary-layer microclimate at the microscopic scale will remain very challenging.

\section{Acknowledgements}

Thijs Defraeye is postdoctoral fellow of the Research Foundation - Flanders (FWO) and acknowledges its support. The authors also thank the Research Council of the KU Leuven (OT project 12/055) for financial support. 
Defraeye T., Verboven P., Derome D., Carmeliet J., Nicolai B., Stomatal transpiration and droplet evaporation on leaf surfaces by a microscale modelling approach, International Journal of Heat and Mass Transfer 65, 180-191. http://dx.doi.org/10.1016/j.ijheatmasstransfer.2013.05.075

\section{$\underline{\text { References }}$}

[1] P.S. Nobel, Physicochemical and Environmental Plant Physiology, third ed., Elsevier Academic Press, London, 2005.

[2] J.A. Berry, D.J. Beerling, P.J. Franks, Stomata: key players in the earth system, past and present, Current Opinion in Plant Biology 13 (2010) 233-240.

[3] F.R. Rijsberman, Water scarcity: Fact or fiction?, Agricultural Water Management 80 (1-3) (2006) 5-22.

[4] J.L. Monteith, Accommodation between transpiring vegetation and the convective boundary layer, Journal of Hydrology 166 (3-4) (1995) 251-263.

[5] D.M. Smith, P.G. Jarvis, Physiological and environmental control of transpiration by trees in windbreaks, Forest Ecology and Management 105 (1-3) (1998) 159-173.

[6] D.M. Smith, P.G. Jarvis, J.C.W. Odongo, Energy budgets of windbreak canopies in the Sahel, Agricultural and Forest Meteorology 86 (1-2) (1997) 33-49.

[7] W.L. Bauerle, J.D. Bowden, Predicting transpiration response to climate change: insights on physiological and morphological interactions that modulate water exchange from leaves to canopies, HortScience 46 (2) (2011) 163-166.

[8] A. Roth-Nebelsick, F. Hassiotou, E.J. Veneklaas, Stomatal crypts have small effects on transpiration: A numerical model analysis, Plant Physiology 151 (2009) 2018-2027.

[9] T. Defraeye, P. Verboven, Q.T. Ho, B. Nicolai, Convective heat and mass exchange predictions at leaf surfaces: applications, methods and perspectives, 2013 Accepted for publication in Computers and Electronics in Agriculture.

[10] A.C. Best, Empirical formulae for the terminal velocity of water drops falling through the atmosphere, Quarterly Journal of the Royal Meteorological Society 76 (329) (1950) 302-311.

[11] J.V. Cross, P.J. Walklate, R.A. Murray, G.M. Richardson, Spray deposits and losses in different sized apple trees from an axial fan orchard sprayer: 2. Effects of spray quality, Crop Protection 20 (4) (2001) 333-343.

[12] B. Blocken, J. Carmeliet, A review of wind-driven rain research in building science, Journal of Wind Engineering and Industrial Aerodynamics 92 (13) (2004) 1079-1130.

[13] T.A. Ebert, R.A. Downer, A different look at experiments on pesticide distribution, Crop Protection 25 (4) (2006) 299-309.

[14] A. Melese Endalew, C. Debaer, N. Rutten, J. Vercammen, M.A. Delele, H. Ramon, B. Nicolai, P. Verboven, Modelling pesticide flow and deposition from air-assisted orchard spraying in orchards: A new integrated CFD approach, Agricultural and Forest Meteorology 150 (10) (2010) 1383-1392.

[15] A. Boehncke, J. Siebers, H.-G. Nolting, Investigations of the evaporation of selected pesticides from natural and model surfaces in field and laboratory, Chemosphere 21 (9) (1990) 1109-1124.

[16]L. Xu, H. Zhu, H.E. Ozkan, H.W. Thistle, Evaporation rate and development of wetted area of water droplets with and without surfactant at different locations on waxy leaf surfaces, Biosystems Engineering 106 (1) (2010) 58-67.

[17] Y. Yu, H. Zhu, J.M. Frantz, M.E. Reding, K.C. Chan, H.E. Ozkan, Evaporation and coverage area of pesticide droplets on hairy and waxy leaves, Biosystems Engineering 104 (3) (2009) 324-334. 
Defraeye T., Verboven P., Derome D., Carmeliet J., Nicolai B., Stomatal transpiration and droplet evaporation on leaf surfaces by a microscale modelling approach, International Journal of Heat and Mass Transfer 65, 180-191. http://dx.doi.org/10.1016/j.ijheatmasstransfer.2013.05.075

[18] T. Haseba, Mass transfer across the boundary layer on plant leaves (1): Preliminary study of water-vapor transfer from a leaf-like flat plate with separated evaporation sources, Journal of Agricultural Meteorology 30 (2) (1974) 45-55.

[19]P.H. Schuepp; Tansley Review No. 59: Leaf boundary layers, New Phytologist 125 (3) (1993) 477-507.

[20]E.U. Schlünder, On the mechanism of the constant drying rate period and its relevance to diffusion controlled catalytic gas phase reactions, Chemical Engineering Science 43 (10) (1988) 2685-2688.

[21] J.N. Cannon, W.B. Krantz, F. Kreith, D. Naot, A study of transpiration from porous flat plates simulating plant leaves, International Journal of Heat and Mass Transfer 22 (3) (1979) 469-483.

[22] M. Casey, T. Wintergerste, ERCOFTAC Special Interest Group on "Quality and Trust in Industrial CFD": Best Practice Guidelines, ERCOFTAC, 2000.

[23] J. Franke, A. Hellsten, H. Schlünzen, B. Carissimo, Best practice guideline for the CFD simulation of flows in the urban environment. COST Action 732: Quality assurance and improvement of microscale meteorological models, Hamburg, Germany, 2007.

[24]P.J. Roache, Perspective: a method for uniform reporting of grid refinement studies, Transactions of the ASME: Journal of Fluids Engineering 116 (3) (1994) 405-413.

[25] M. Gad-el-Hak, The fluid mechanics of microdevices - the Freeman scholar lecture, Journal of Fluids Engineering 121 (1) (1999) 5-33.

[26] M. Gad-el-Hak, Differences between liquid and gas transport at the microscale, Bulletin of the Polish Academy of Sciences 53 (4) (2005) 301-316.

[27] M. Gad-el-Hak, Gas and liquid transport at the microscale, Heat Transfer Engineering 27 (4) (2006) 13-29.

[28] S.G. Jennings, The mean free path in air, Journal of Aerosol Science 19 (2) (1988) 159-166.

[29] B.E. Launder, D.B. Spalding, The numerical computation of turbulent flows, Computer Methods in Applied Mechanics and Engineering 3 (2) (1974) 269-289.

[30] ANSYS Fluent 13 2010. Ansys Fluent 13.0 User’s Guide \& Theory Guide. Ansys Inc, Canonsburg, Pennsylvania.

[31]T. Defraeye, B. Blocken, J. Carmeliet, Analysis of convective heat and mass transfer coefficients for convective drying of a porous flat plate by conjugate modelling, International Journal of Heat and Mass Transfer 55 (1-3) (2012) 112-124.

[32] T. Defraeye, B. Blocken, D. Derome, B. Nicolai, J. Carmeliet, Convective heat and mass transfer modelling at air-porous material interfaces: overview of existing methods and relevance, Chemical Engineering Science 74 (2012) 49-58.

[33] T.H. Chilton, A.P. Colburn, Mass transfer (absorption) coefficients, Industrial and Engineering Chemistry 26 (11) (1934) 1183-1187.

[34] A. Kondjoyan, J.D. Daudin, Determination of transfer coefficients by psychrometry, International Journal of Heat and Mass Transfer 36 (7) (1993) 1807-1818.

[35] H.G. Jones, Plants and microclimate: a quantitative approach to environmental plant physiology, second ed., Cambridge University Press, New York, 1992.

[36]F.R. Menter, Two-equation eddy-viscosity turbulence models for engineering applications, AIAA Journal 32 (8) (1994) 1598-1605. 
Defraeye T., Verboven P., Derome D., Carmeliet J., Nicolai B., Stomatal transpiration and droplet evaporation on leaf surfaces by a microscale modelling approach, International Journal of Heat and Mass Transfer 65, 180-191. http://dx.doi.org/10.1016/j.ijheatmasstransfer.2013.05.075

[37] T. Defraeye, B. Blocken, J. Carmeliet, CFD analysis of convective heat transfer at the surfaces of a cube immersed in a turbulent boundary layer, International Journal of Heat and Mass Transfer 53 (1-3) (2010) 297 308.

[38] T. Defraeye, B. Blocken, E. Koninckx, P. Hespel, J. Carmeliet, Computational fluid dynamics analysis of cyclist aerodynamics: Performance of different turbulence-modelling and boundary-layer modelling approaches, Journal of Biomechanics 43 (12) (2010) 2281-2287.

[39] T. Defraeye, E. Herremans, P. Verboven, J. Carmeliet, B. Nicolai, Convective heat and mass exchange at surfaces of horticultural products: a microscale CFD modelling approach, Agricultural and Forest Meteorology 162-163 (2012) 71-84.

[40] H. Schlichting, K. Gersten, Boundary Layer Theory, eight ed., Springer-Verlag Berlin Heidelberg, Germany, 2000.

[41] A. Belhamri, J.P. Fohr, Heat and mass transfer along a wetted porous plate in an airstream, AIChE Journal 42 (7) (1996) 1833-1843.

[42] M. Suzuki, S. Maeda, On the mechanism of drying of granular beds, Journal of Chemical Engineering of Japan 1 (1) (1968) 26-31.

[43] T. Cebeci, P. Bradshaw, Physical and Computational aspects of Convective Heat Transfer, first ed., SpringerVerlag New York Inc., USA, 1984.

[44] R.B. Dean, Reynolds number dependence of skin friction and other bulk flow variables in two-dimensional rectangular duct flow, Transactions of the ASME: Journal of Fluids Engineering 100 (1978) 215-223.

[45] M.Y. Leclerc, P.H. Schuepp, G.W. Thurtell, Electrochemical simulations of mass transfer from isolated wet spots and droplets on realistic fluttering leaves, Boundary-Layer Meteorology 34 (1986) 399-410.

[46] Q.T. Ho, J. Carmeliet, A.K. Datta, T. Defraeye, M.A. Delele, E. Herremans, L. Opara, H. Ramon, E. Tijskens, R. van der Sman, P. Van Liedekerke, P. Verboven, B. Nicolai, Multiscale modeling in food engineering, Journal of Food Engineering 114 (3) (2012) 279-291.

[47] Q.T. Ho, P. Verboven, B.E. Verlinden, E. Herremans, M. Wevers, J. Carmeliet, B. Nicolai, A threedimensional multiscale model for gas exchange in fruit, Plant Physiology 155 (3) (2011) 1158-1168.

[48] D.R. Butler, Mass transfer from discrete water drops on leaves in a cereal canopy, Boundary-Layer Meteorology 53 (1-2) (1990) 33-42. 
Defraeye T., Verboven P., Derome D., Carmeliet J., Nicolai B., Stomatal transpiration and droplet evaporation on leaf surfaces by a microscale modelling approach, International Journal of Heat and Mass

Transfer 65, 180-191. http://dx.doi.org/10.1016/j.ijheatmasstransfer.2013.05.075

\section{Supplementary material}

Appendix 1: Details of computational grid

Appendix 2: Analogy between heat and mass transfer 
Defraeye T., Verboven P., Derome D., Carmeliet J., Nicolai B., Stomatal transpiration and droplet evaporation on leaf surfaces by a microscale modelling approach, International Journal of Heat and Mass

Transfer 65, 180-191. http://dx.doi.org/10.1016/j.ijheatmasstransfer.2013.05.075

\section{$\underline{\text { Figures }}$}

$\underline{\text { Figures }}$

a) Precursor domain

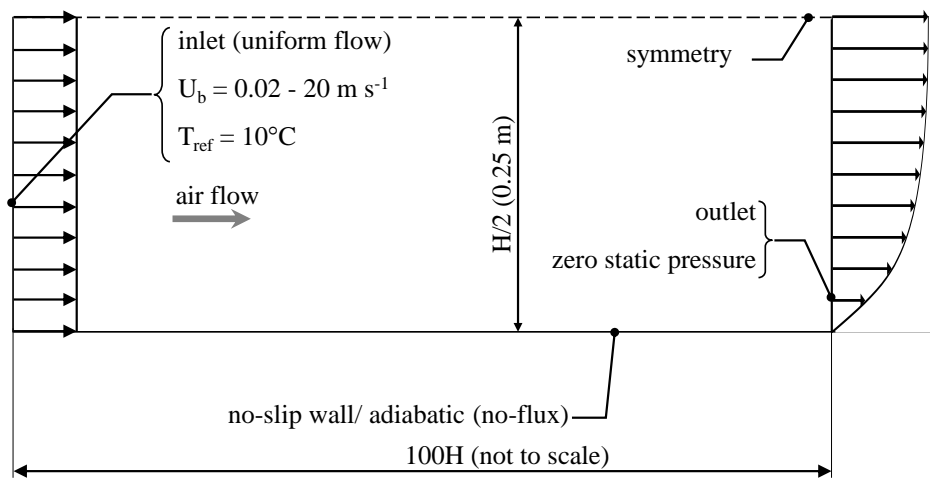

b) Leaf domain

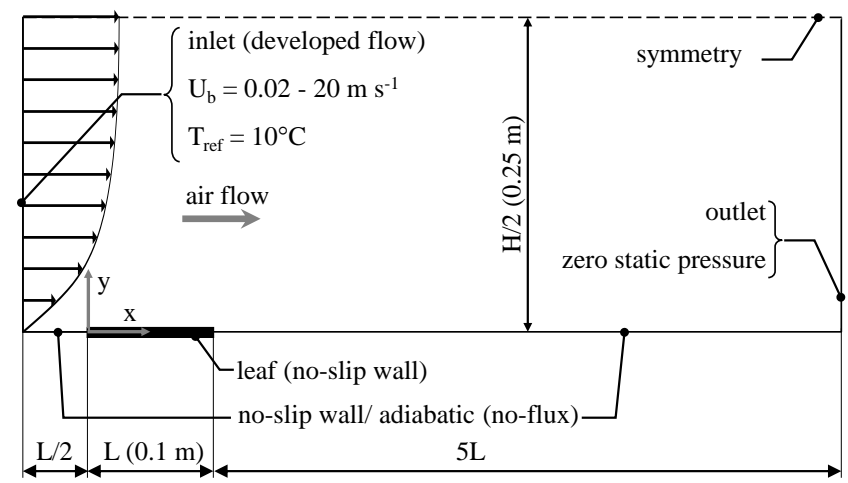

Figure 1. Two-dimensional computational domain and boundary conditions for: (a) precursor simulations; (b) leaf simulations. 
Defraeye T., Verboven P., Derome D., Carmeliet J., Nicolai B., Stomatal transpiration and droplet evaporation on leaf surfaces by a microscale modelling approach, International Journal of Heat and Mass

Transfer 65, 180-191. http://dx.doi.org/10.1016/j.ijheatmasstransfer.2013.05.075

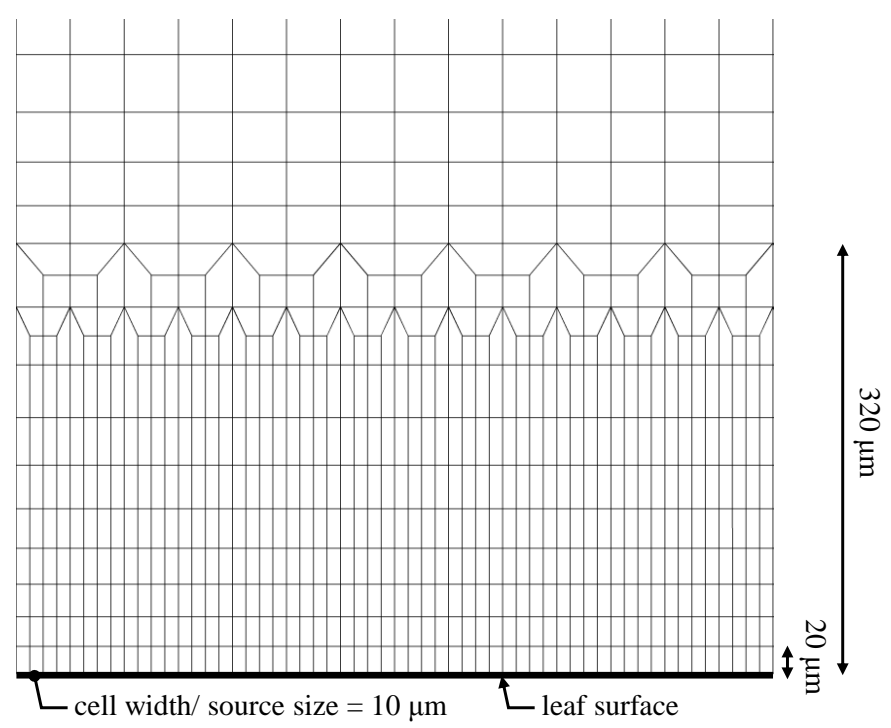

Figure 2. Computational grid in the boundary-layer region in the proximity of the leaf surface. 
Defraeye T., Verboven P., Derome D., Carmeliet J., Nicolai B., Stomatal transpiration and droplet evaporation on leaf surfaces by a microscale modelling approach, International Journal of Heat and Mass

Transfer 65, 180-191. http://dx.doi.org/10.1016/i.ijheatmasstransfer.2013.05.075
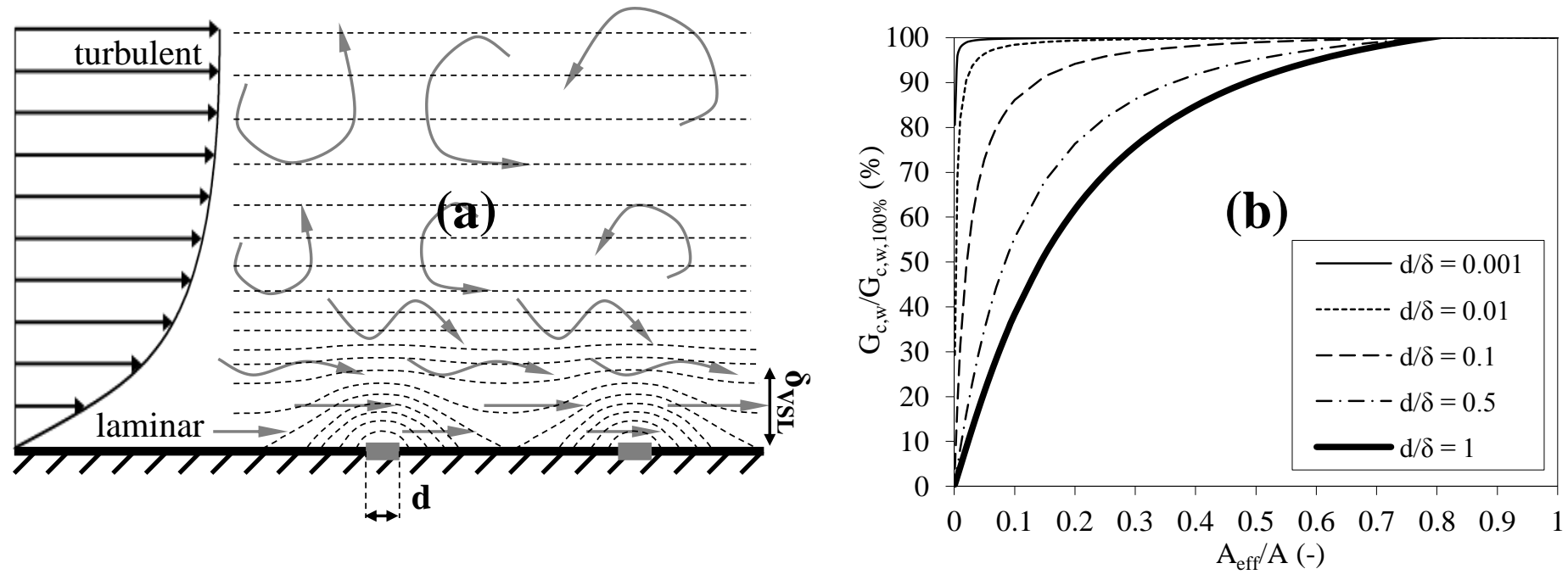

Figure 3. (a) Water vapour concentration contours in the boundary layer over a wall surface with discretelydistributed moisture sources (indicated in grey) with indication of $d$ and $\delta_{V S L}$ and also laminar and turbulent regions in the boundary layer; (b) Mass flow rate as a function of the surface coverage ratio $\left(C R=A_{\text {eff }} / A\right)$ according to Eqs. (10)-(11) from Schlünder [20] for different $d / \delta_{V S L}$ ratios (adjusted from Defraeye et al. [39], but now with $d=2 r$ ). The mass flow rate is scaled with that of a surface with a coverage ratio of $100 \%$. 
Defraeye T., Verboven P., Derome D., Carmeliet J., Nicolai B., Stomatal transpiration and droplet evaporation on leaf surfaces by a microscale modelling approach, International Journal of Heat and Mass Transfer 65, 180-191. http://dx.doi.org/10.1016/j.ijheatmasstransfer.2013.05.075

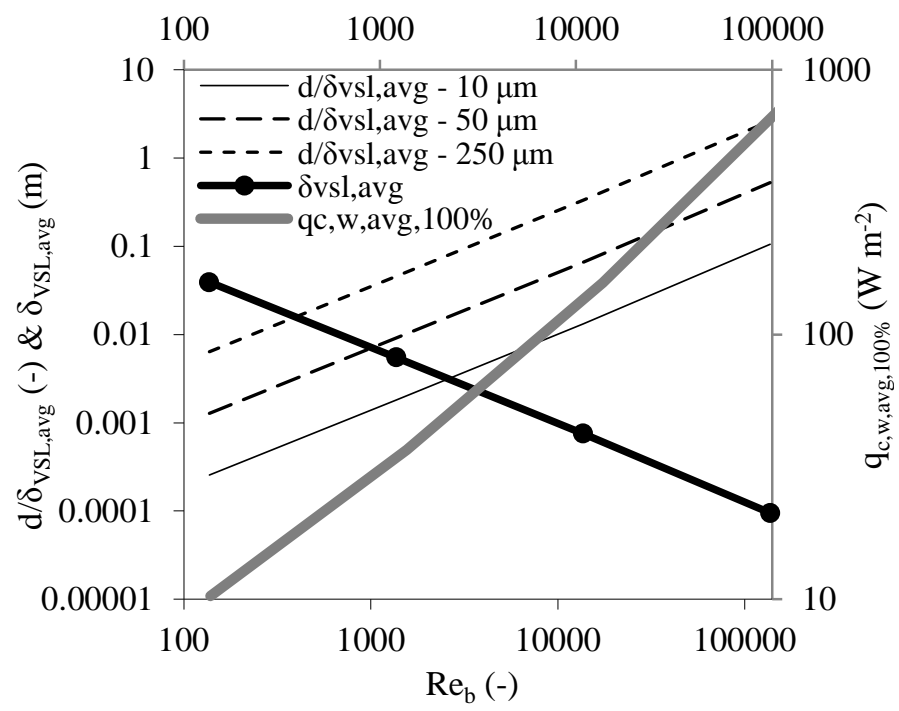

Figure 4. Surface-averaged viscous sublayer thickness $\delta_{V S L, a v g}$ (bold black line), microscopic Sherwood numbers $\left(d / \delta_{V S L, a v g}\right.$ ratios) and surface-averaged (heat) flux ( $\left(q_{c, w}\right.$, bold grey line) as a function of the bulk Reynolds number. For $d / \delta_{V S L, a v g}$, results for different source sizes are presented $(10 \mu \mathrm{m}, 50 \mu \mathrm{m}$ and $250 \mu \mathrm{m})$. Logarithmic scaling is used. 
Defraeye T., Verboven P., Derome D., Carmeliet J., Nicolai B., Stomatal transpiration and droplet evaporation on leaf surfaces by a microscale modelling approach, International Journal of Heat and Mass

Transfer 65, 180-191. http://dx.doi.org/10.1016/j.ijheatmasstransfer.2013.05.075

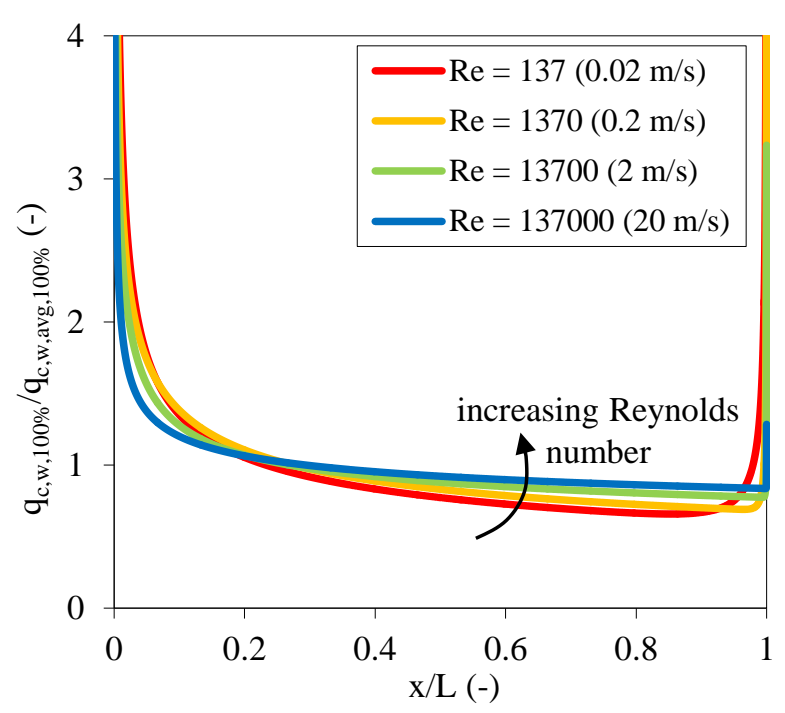

Figure 5. Local scalar flux distribution over the leaf surface $\left(q_{c, w, 100 \%}\right)$, scaled with the surface-averaged flux over the leaf $\left(q_{c, w, a v g, 100 \%)}\right)$ as a function of the distance from the leading edge $(x / L)$ for different bulk Reynolds numbers for a leaf with uniform coverage (CR 100\%).

ONLY INTENDED FOR COLOUR ON WEB, NOT IN PRINT 
Defraeye T., Verboven P., Derome D., Carmeliet J., Nicolai B., Stomatal transpiration and droplet evaporation on leaf surfaces by a microscale modelling approach, International Journal of Heat and Mass

Transfer 65, 180-191. http://dx.doi.org/10.1016/j.ijheatmasstransfer.2013.05.075
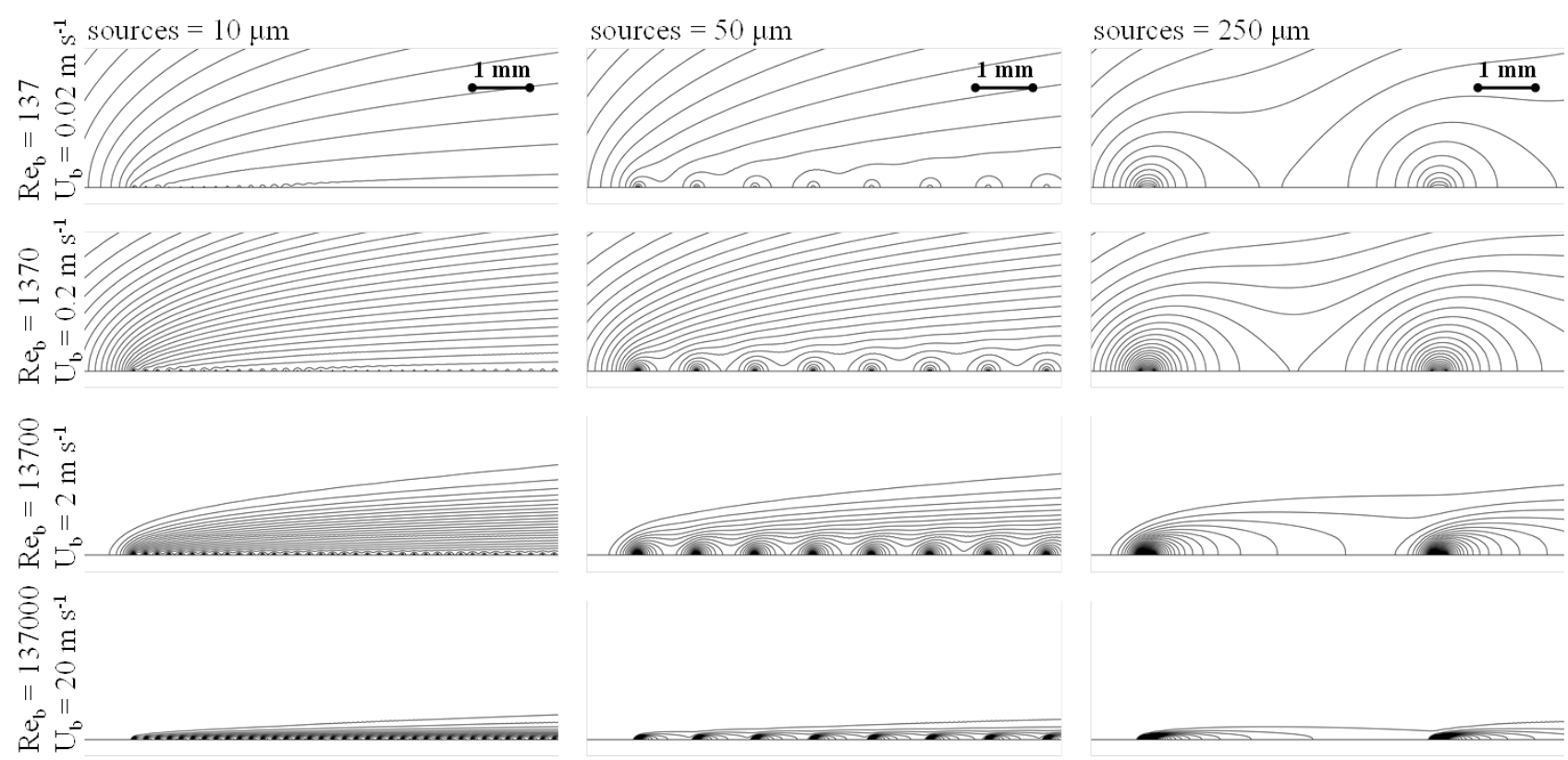

Figure 6. Scalar concentration contours in the boundary layer at the leading edge of the leaf, on which discretelydistributed scalar sources are present. For each source size, results at different air speeds are shown for a coverage ratio of $5 \%$. The steps between the contours are the same for all figures (a total of 30 contours over a temperature range from $10-20^{\circ} \mathrm{C}$ ). 
Defraeye T., Verboven P., Derome D., Carmeliet J., Nicolai B., Stomatal transpiration and droplet evaporation on leaf surfaces by a microscale modelling approach, International Journal of Heat and Mass Transfer 65, 180-191. http://dx.doi.org/10.1016/i.ijheatmasstransfer.2013.05.075
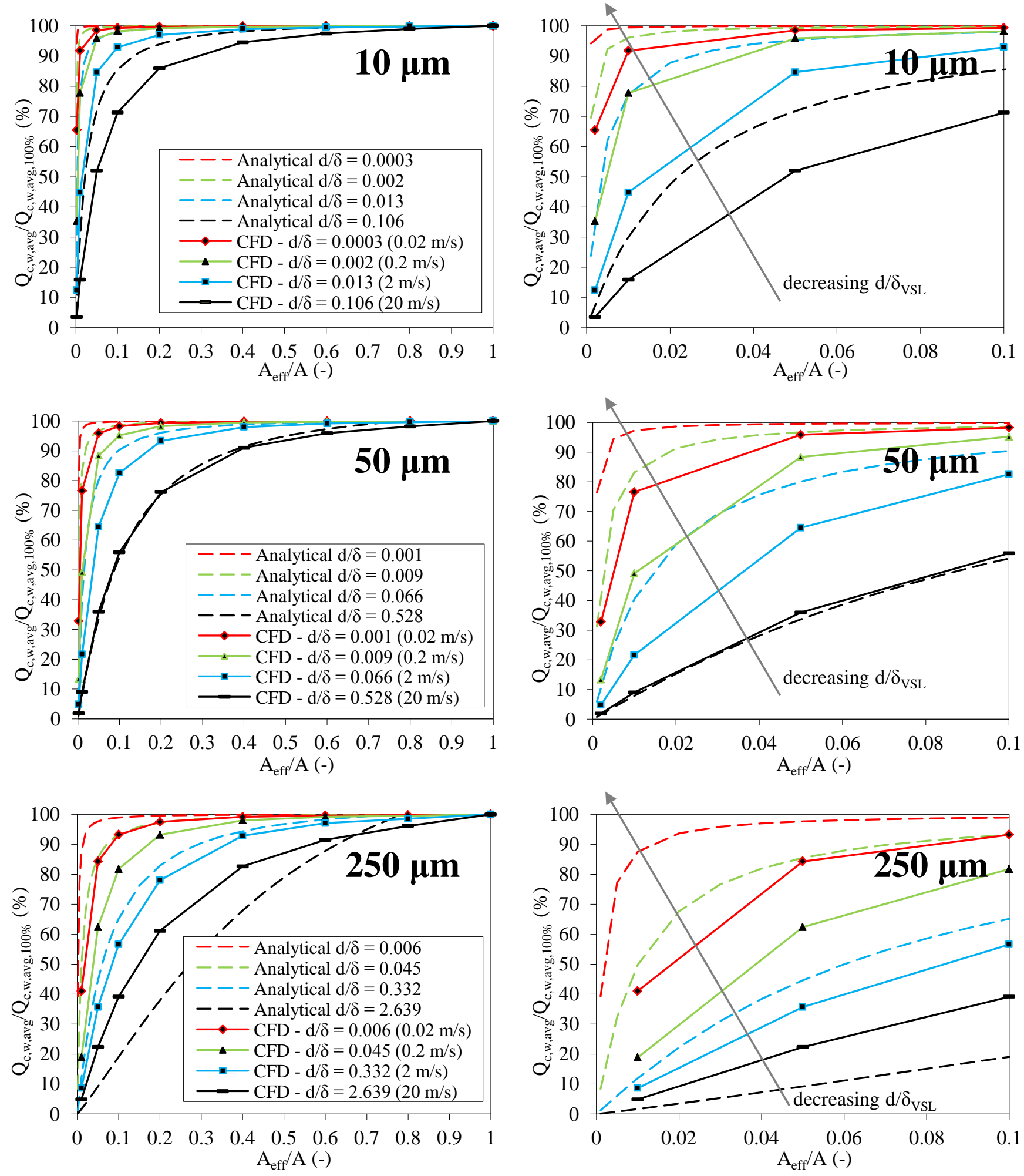

Figure 7. Surface-averaged convective scalar flows at the leaf surface as a function of the coverage ratio for different air speeds $\left(U_{b}\right.$, i.e., $d / \delta_{V S L}$ ratios), for three source sizes separately: $10 \mu \mathrm{m}, 50 \mu \mathrm{m}$ and $250 \mu \mathrm{m}$. The corresponding analytical solutions of Schlünder (Eqs. (10)-(11)) for the specific $d / \delta_{V S L}$ ratio (with $d=2 r$ ) are presented by dotted lines. Left: coverage ratios from 0-100\%; right: coverage ratios from 0-10\%. The flows are scaled with the surface-averaged scalar flow for a coverage ratio of $100 \%\left(Q_{c, w, a v g, 100 \%}\right)$.

ONLY INTENDED FOR COLOUR ON WEB, NOT IN PRINT 
Defraeye T., Verboven P., Derome D., Carmeliet J., Nicolai B., Stomatal transpiration and droplet evaporation on leaf surfaces by a microscale modelling approach, International Journal of Heat and Mass

Transfer 65, 180-191. http://dx.doi.org/10.1016/j.ijheatmasstransfer.2013.05.075 
Defraeye T., Verboven P., Derome D., Carmeliet J., Nicolai B., Stomatal transpiration and droplet evaporation on leaf surfaces by a microscale modelling approach, International Journal of Heat and Mass Transfer 65, 180-191. http://dx.doi.org/10.1016/i.ijheatmasstransfer.2013.05.075
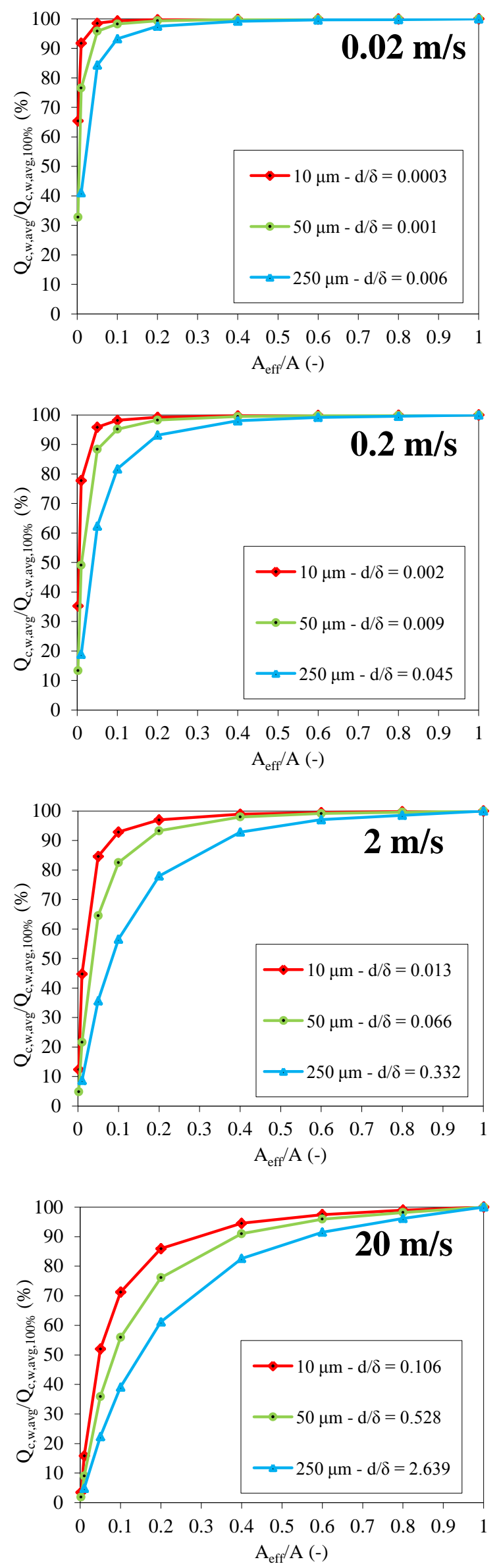
Defraeye T., Verboven P., Derome D., Carmeliet J., Nicolai B., Stomatal transpiration and droplet evaporation on leaf surfaces by a microscale modelling approach, International Journal of Heat and Mass Transfer 65, 180-191. http://dx.doi.org/10.1016/j.ijheatmasstransfer.2013.05.075

Figure 8. Surface-averaged convective scalar flows at the leaf surface as a function of the coverage ratio for different source sizes (i.e., $d / \delta_{V S L}$ ratios), for each air speed $\left(U_{b}\right)$ separately: $0.02 \mathrm{~m} \mathrm{~s}^{-1}, 0.2 \mathrm{~m} \mathrm{~s}^{-1}, 2 \mathrm{~m} \mathrm{~s}^{-1}, 20 \mathrm{~m} \mathrm{~s}^{-1}$. The flows are scaled with the surface-averaged scalar flow for a coverage ratio of $100 \%\left(Q_{c, w, a v g, 100 \%}\right)$. ONLY INTENDED FOR COLOUR ON WEB, NOT IN PRINT 
Defraeye T., Verboven P., Derome D., Carmeliet J., Nicolai B., Stomatal transpiration and droplet evaporation on leaf surfaces by a microscale modelling approach, International Journal of Heat and Mass Transfer 65, 180-191. http://dx.doi.org/10.1016/j.ijheatmasstransfer.2013.05.075

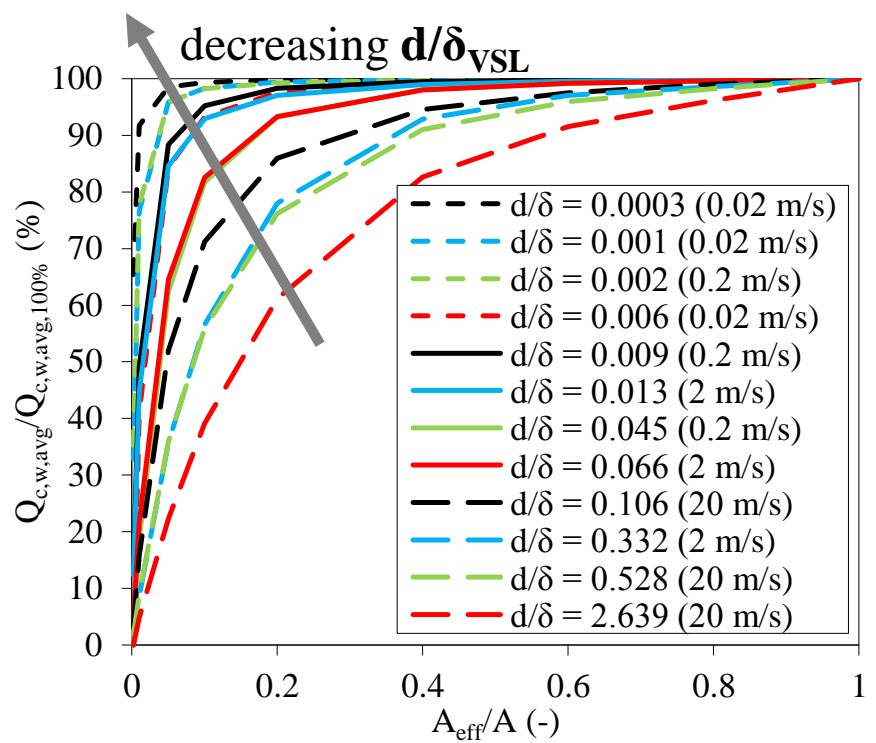

Figure 9. Surface-averaged convective scalar flows at the leaf surface as a function of the coverage ratio for all microscopic Sherwood numbers (i.e., $d / \delta_{V S L}$ ratios). The flows are scaled with the surface-averaged scalar flow for a coverage ratio of $100 \%\left(Q_{c, w, a v g, 100 \%}\right)$.

ONLY INTENDED FOR COLOUR ON WEB, NOT IN PRINT 
Defraeye T., Verboven P., Derome D., Carmeliet J., Nicolai B., Stomatal transpiration and droplet evaporation on leaf surfaces by a microscale modelling approach, International Journal of Heat and Mass Transfer 65, 180-191. http://dx.doi.org/10.1016/i.ijheatmasstransfer.2013.05.075
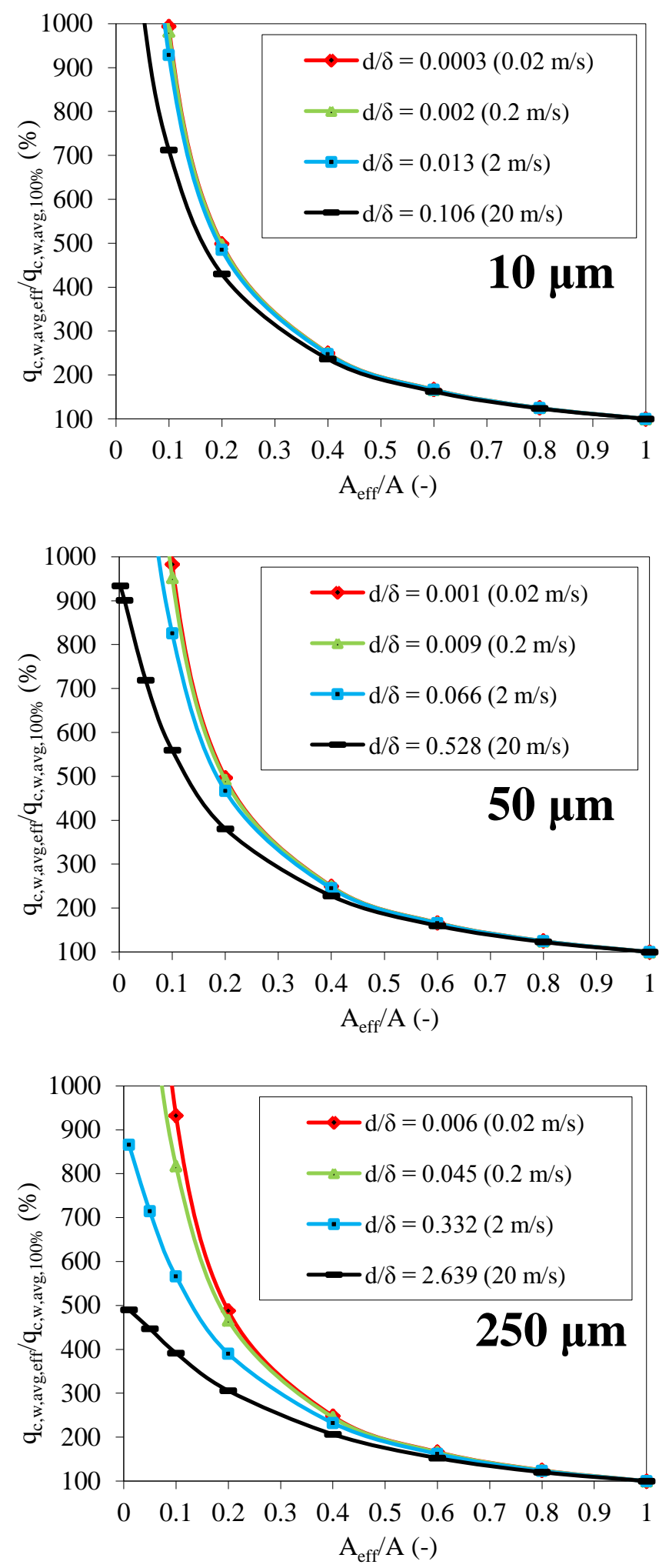

Figure 10. Effective convective scalar fluxes at the leaf surface $\left(q_{c, w, a v g, e f f}\right)$, averaged only over the sources on the leaf thus over $A_{e f f}$, as a function of the coverage ratio for different air speeds ( $U_{b}$, i.e., $d / \delta_{V S L}$ ratios), for three source sizes separately: $10 \mu \mathrm{m}, 50 \mu \mathrm{m}$ and $250 \mu \mathrm{m}$. The flows are scaled with the surface-averaged scalar flux for a coverage ratio of $100 \%\left(q_{c, w, a v g, 100 \%}\right)$. Note there is some overlap between the different curves for a source size of $10 \mu \mathrm{m}$.

ONLY INTENDED FOR COLOUR ON WEB, NOT IN PRINT 
Defraeye T., Verboven P., Derome D., Carmeliet J., Nicolai B., Stomatal transpiration and droplet evaporation on leaf surfaces by a microscale modelling approach, International Journal of Heat and Mass

Transfer 65, 180-191. http://dx.doi.org/10.1016/j.ijheatmasstransfer.2013.05.075

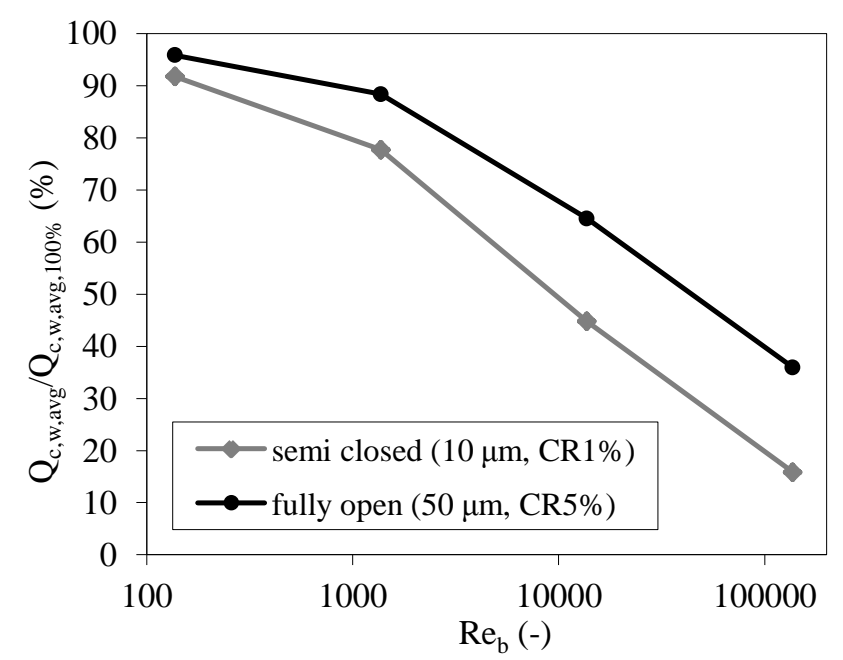

Figure 11. Surface-averaged convective scalar flows at the leaf surface as a function of the bulk Reynolds number for different stomatal apertures (each case has 100 stomata on the leaf surface). The flows are scaled with the surface-averaged scalar flow for a coverage ratio of $100 \%\left(Q_{c, w, a v g, 100 \%}\right)$. Logarithmic scaling is used for the Reynolds number. 
Defraeye T., Verboven P., Derome D., Carmeliet J., Nicolai B., Stomatal transpiration and droplet evaporation on leaf surfaces by a microscale modelling approach, International Journal of Heat and Mass

Transfer 65, 180-191. http://dx.doi.org/10.1016/i.ijheatmasstransfer.2013.05.075

Table 1. Experimental studies on convective transfer at discretely-distributed sources at leaf surfaces.

\begin{tabular}{|c|c|c|c|c|c|c|c|c|c|c|}
\hline Author & Subject & Setup & $\begin{array}{l}\text { Leaf type, } \\
\text { morphology } \\
\text { and size }\end{array}$ & Method & BCs & $\begin{array}{l}\text { Flow } \\
\text { configuration } \\
\text { \& regime }\end{array}$ & $\begin{array}{l}\text { Coverage } \\
\text { ratio }(\%)\end{array}$ & Source & $\begin{array}{l}\text { Air speed } \\
\text { \& Re }\end{array}$ & Remarks \\
\hline $\begin{array}{l}\text { Haseba } \\
{[18]}\end{array}$ & stomata & WT & $\begin{array}{l}\text { flat plate with } \\
2 \mathrm{D} \text { wet strips } \\
(L=5-10 \mathrm{~cm})\end{array}$ & $\begin{array}{l}\text { weighing } \\
\text { method }\end{array}$ & wet strips & $\begin{array}{l}\text { parallel flow, } \\
\text { forced }\end{array}$ & $10-100$ & $\begin{array}{l}\text { rectan., } \\
L=1- \\
10 \mathrm{~mm}\end{array}$ & $0.5-8 \mathrm{~m} \mathrm{~s}^{-1}$ & $\begin{array}{l}\text { strip spacing; } \\
\text { analytical } \\
\text { analysis }\end{array}$ \\
\hline $\begin{array}{l}\text { Cannon } \\
\text { et al. } \\
{[21]}\end{array}$ & stomata & WT & $\begin{array}{l}\text { perforated } \\
\text { plates (sheet } \\
\text { metal \& } \\
\text { polycarbonate } \\
\text { membrane, } \\
L=5-20 \mathrm{~cm} \text { ) }\end{array}$ & $\begin{array}{l}\text { weighing } \\
\text { method }\end{array}$ & $\begin{array}{l}\text { wet surface in } \\
\text { cavity below } \\
\text { perforated } \\
\text { plate }\end{array}$ & $\begin{array}{l}\text { parallel\& } \\
\text { oblique flow, } \\
\text { forced }\end{array}$ & $0.5-5$ & $\begin{array}{l}\text { circ., } \\
D=10- \\
1180 \mu \mathrm{m}\end{array}$ & $\begin{array}{l}\operatorname{Re}_{\mathrm{L}} \approx 4000- \\
60000\end{array}$ & $\begin{array}{l}\text { BL \& } \\
\text { internal leaf } \\
\text { resistances; } \\
\text { source } \\
\text { size/density; } \\
\text { analytical } \\
\text { analysis }\end{array}$ \\
\hline $\begin{array}{l}\text { Leclerc } \\
\text { et al. } \\
{[45]}\end{array}$ & droplets & $\begin{array}{l}\text { EC- } \\
\text { FT }\end{array}$ & $\begin{array}{l}\text { plastic-coated } \\
\text { real \& artif. } \\
\text { leaves with } \\
\text { solder drops } \\
(L=5 \mathrm{~cm}) \& \\
\text { circuit board } \\
\text { with isolated } \\
\text { etched discs } \\
\left(A=100 \mathrm{~cm}^{2}\right) \\
\end{array}$ & $\begin{array}{l}\text { electroch. } \\
\text { method }\end{array}$ & $\begin{array}{l}\text { const. } \\
\text { concentration } \\
\text { ferro-cyanide } \\
\text { ions }\end{array}$ & $\begin{array}{l}\text { parallel \& } \\
\text { oblique flow, } \\
\text { forced }\end{array}$ & - & $\begin{array}{l}\text { circ., } \\
D=4- \\
7 \mathrm{~mm} \\
\text { (drops) } \\
\& \\
D=6.9- \\
8.4 \mathrm{~mm} \\
\text { (discs) }\end{array}$ & $\begin{array}{l}\sim 10^{-2}-10^{-} \\
{ }^{1} \mathrm{~m} \mathrm{~s}^{-1}\end{array}$ & $\begin{array}{l}\text { wet and dry } \\
\text { leaves; leaf } \\
\text { flutter }\end{array}$ \\
\hline $\begin{array}{l}\text { Butler } \\
{[48]}\end{array}$ & droplets & field & $\begin{array}{l}\text { wheat leaf with } \\
\text { single droplet }\end{array}$ & $\begin{array}{l}\text { droplet } \\
\text { temp. }\end{array}$ & $\begin{array}{l}\text { droplet on } \\
\text { leaf }\end{array}$ & natural env. & - & $\begin{array}{l}\text { circ., } \\
D=2.7- \\
5.4 \mathrm{~mm}, \\
V=10- \\
50 \mathrm{~mm}^{3}\end{array}$ & $\begin{array}{l}0.3-2.4 \mathrm{~m} \\
\mathrm{~s}^{-1}\end{array}$ & $\begin{array}{l}\text { source size; } \\
\text { air speed }\end{array}$ \\
\hline
\end{tabular}

